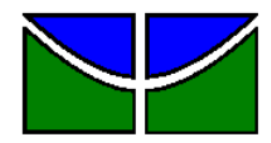

Universidade de Brasília

Faculdade de Economia, Administração e Contabilidade

Departamento de Administração

FILIPE GOMES MIZIARA

Análise Comparativa da Poluição Ambiental Sonora dos Sistemas de Transporte de Passageiros Ferroviário e Rodoviário.

Brasília - DF 
FILIPE GOMES MIZIARA

\section{Análise Comparativa da Poluição Ambiental Sonora dos Sistemas de Transporte de Passageiros Ferroviário e Rodoviário.}

Monografia apresentada ao Departamento de Administração como requisito parcial à obtenção do título de Bacharel em Administração.

Professora Orientadora: Dra. Clarissa Melo Lima

Brasília - DF 
FILIPE GOMES MIZIARA

\section{Análise Comparativa da Poluição Ambiental Sonora dos Sistemas de Transporte de Passageiros Ferroviário e Rodoviário.}

A Comissão Examinadora, abaixo identificada, aprova o Trabalho de Conclusão do Curso de Administração da Universidade de Brasília do aluno

Filipe Gomes Miziara

Dra. Clarissa Melo Lima

Professora-Orientadora

Dr. Victor Rafael Rezende Celestino Professor-Examinador
Dr. Evaldo Cesar Cavalcante Rodrigues

Professor-Examinador

Brasília - DF 
Dedico o presente trabalho à minha família, que sempre foi, e sempre será o alicerce que norteia todas as minhas conquistas. Aos meus amados pais, Fábio e Silvana, e aos meus queridos irmãos, Matheus e Pedro. 


\section{AGRADECIMENTOS}

Não poderia realizar esse trabalho sem agradecer à Universidade de Brasília, que por quase 6 anos fez parte do meu cotidiano, e me fez vivenciar experiências que moldaram meu caráter e meu comportamento perante o mundo. A todo corpo docente, que dentro das características individuais de cada um, ministraram excelentes aulas, transmitindo conteúdo da mais alta qualidade acadêmica, justificando o status de excelente universidade atribuído à UnB, especialmente à Professora Clarissa, que tornou possível, com toda a sua paciência, esforço e sabedoria, que esse trabalho fosse concluído.

Ao meu pai, que à base do suor, da amizade e do companheirismo, me inspirou, e continua a me inspirar em tudo que eu faço na vida, sendo o maior exemplo de homem que eu poderia ter. À minha mãe, que construiu uma família com o que havia de melhor nela, que deu o que tinha e o que não tinha para me dar educação, me fazer feliz e sólido, que abriu mão de sonhos e conquistas próprias, para vibrar como se fossem suas, as conquistas dos seus filhos. Aos meus irmãos, com quem eu tive o prazer de estar ao meu lado em muitos semestres na Universidade, e que são parte essencial na conclusão desta etapa da minha vida, e que por meio da amizade e do respeito são dois pilares que sustentam minha vida. 


\section{RESUMO}

A pesquisa consiste em um levantamento e posterior análise da poluição sonora oriunda dos modais de transporte coletivo rodoviário e ferroviário do Distrito Federal, em específico na Região Administrativa de Águas Claras. Para isso, foi aplicada uma metodologia de aferição em campo dos ruídos emitidos pelos referidos meios de transporte de passageiros. Com escalas preocupantes de extensão, as consequências da poluição sonora no organismo humano são alvo constante de estudos e por consequência, de alertas dos órgãos competentes pela manutenção da saúde em escala global. O trabalho foi realizado com o auxílio de um decibelímetro, aparelho medidor de ruídos, e ocorreu em pontos onde a concentração da poluição sonora ocorre de maneira preponderante, de acordo com a proximidade do modal estudado, ou seja, nas avenidas, próximas aos veículos automotores, e ao lado do trilho do metrô. Por se tratar de um centro urbano com densidade demográfica extremamente alta, e com particularidades de organização, a cidade de Águas Claras concentra todas as características necessárias para que fosse realizada a pesquisa da problemática em questão, incluindo as consequências causadas à saúde humana.

Palavras-chave: 1. Poluição Sonora 2. Águas Claras 3. Transporte Coletivo 4. Mobilidade Urbana 5. Planejamento Urbano 6. Transporte no Distrito Federal 


\begin{abstract}
The research consists of a survey and subsequent analysis of the noise pollution originating from the modalities of collective transportation by road and rail of the Federal District, specifically in the Administrative Region of Águas Claras. For this, a methodology was used to measure the noises emitted by said means of passenger transport in the field. With worrying scales of extension, the consequences of noise pollution in the human body are a constant target of studies and, consequently, warnings of the competent organs for the maintenance of health on a global scale. The work was performed with the aid of a decibel meter, a noise meter, and it occurred at points where the concentration of noise pollution occurs predominantly, according to the proximity of the studied modality, that is, in the avenues, close to the motor vehicles, and next to the subway rail. Because it is an urban center with extremely high population density, and with particularities of organization, the administrative region of Águas Claras concentrates all the necessary characteristics to carry out the research of the problematic in question, including the consequences caused to human health.
\end{abstract}

Keywords: 1. Sound Pollution 2. Clear Waters 3. Collective Transportation 4. Urban Mobility 5. Urban Planning 6. Transportation in the Federal District 


\section{RESUMEN}

La investigación consiste en un levantamiento y posterior análisis de la contaminación sonora oriunda de los modales de transporte colectivo viario y ferroviario del Distrito Federal, en específico en la Región Administrativa de Aguas Claras. Para ello, se aplicó una metodología de medición en campo de los ruidos emitidos por dichos medios de transporte de pasajeros. Con las escalas preocupantes de extensión, las consecuencias de la contaminación sonora en el organismo humano son objeto constante de estudios y por consecuencia, de alertas de los órganos competentes por el mantenimiento de la salud a escala global. El trabajo fue realizado con el auxilio de un decibelímetro, aparato medidor de ruidos, y ocurrió en puntos donde la concentración de la contaminación sonora ocurre de manera preponderante, de acuerdo con la proximidad del modal estudiado, o sea, en las avenidas, próximas a los vehículos automotores y al lado del camino del metro. Por tratarse de un centro urbano con densidad demográfica extremadamente alta, y con particularidades de organización, la región administrativa de Aguas Claras concentra todas las características necesarias para que se realizara la investigación de la problemática en cuestión, incluyendo las consecuencias causadas a la salud humana.

Palabras clave: 1. Contaminación Sonora 2. Aguas Claras 3. Transporte Colectivo 4. Movilidad Urbana 5. Planificación Urbana 6. Transporte en el Distrito Federal 


\section{LISTA DE TABELAS}

Tabela 1 - Quadro de Taxonomia ............................................................ 17

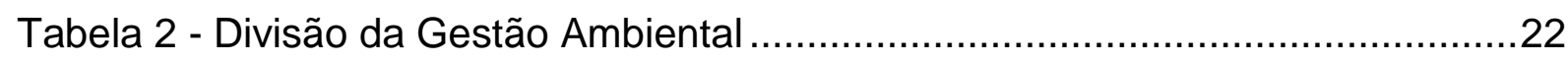

Tabela 3 - Evolução Frota de Veículos.................................................... 25

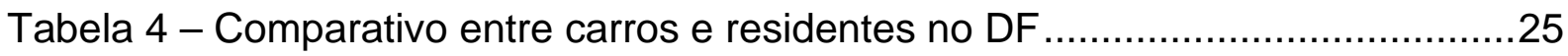

Tabela 5 - Nível de critério de avaliação NCA para ambientes externos, em dB(A) 28

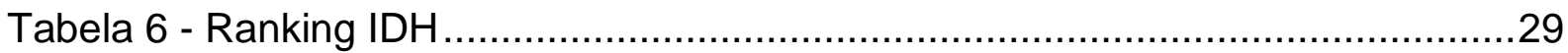

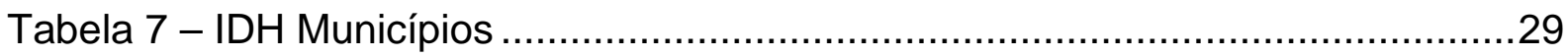

Tabela 8 - Locomoção Habitantes Águas Claras ............................................. 37

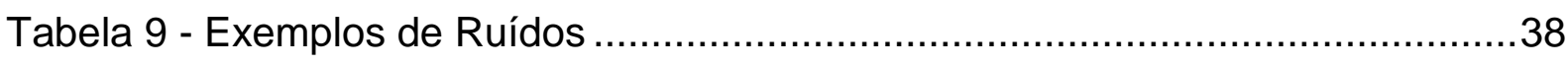

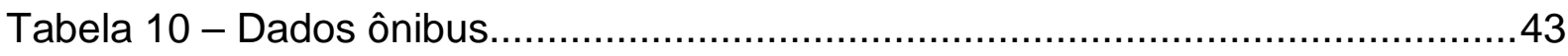

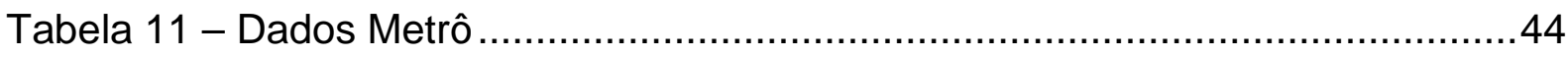

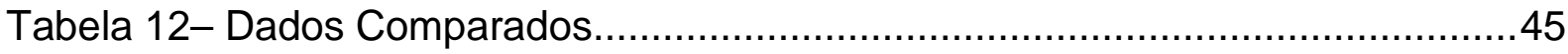

Tabela 13 - Comparativo Legislação .................................................. 46 


\section{LISTA DE FIGURAS}

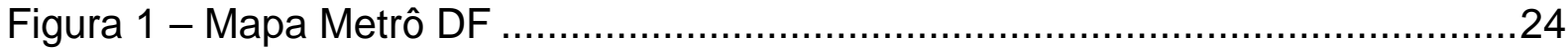

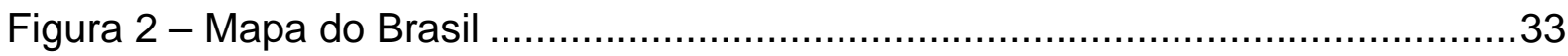

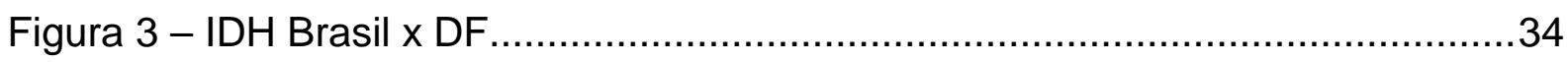

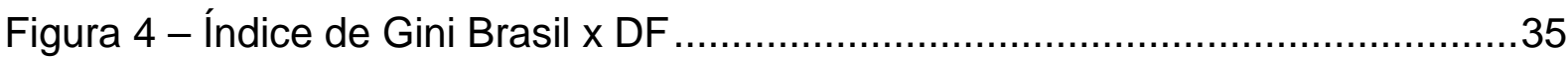

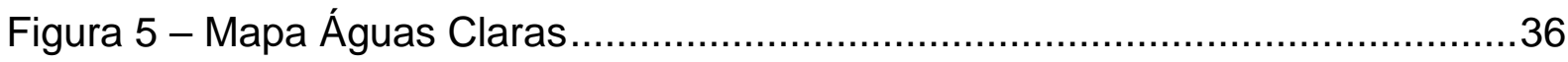

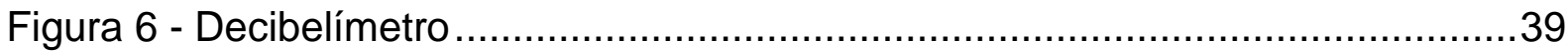

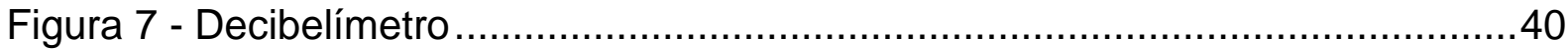

Figura 8 - Ponto de Coleta Metroviário .....................................................41

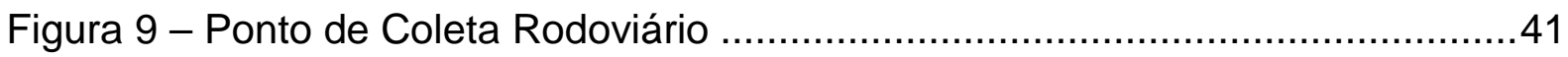

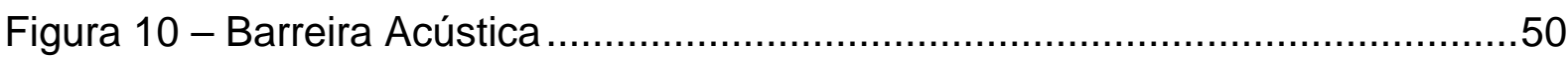




\section{LISTA DE SIGLAS}

ABNT - Associação Brasileira de Normas e Técnicas

dB - Decibéis

CONAMA - Conselho Nacional do Meio Ambiente

DETRAN - Departamento de Trânsito

DF - Distrito Federal

IBGE - Instituto Brasileiro de Geografia e Estatística

IDH - Índice de Desenvolvimento Humano

MMA - Ministério do Meio Ambiente

ONG'S - Organizações Não Governamentais

ONU - Organização das Nações Unidas

OMS - Organização Mundial da Saúde

PDAD - Pesquisa Distrital por Amostra de Domicílios

PNUD - Programa das Nações Unidas para o Desenvolvimento

RA - Região Administrativa

RDH - Relatório de Desenvolvimento Urbano

SGA - Sistema de Gestão Ambiental

STJ - Superior Tribunal de Justiça

UE - União Européia

WHO - World Health Organization 


\section{SUMÁRIO}

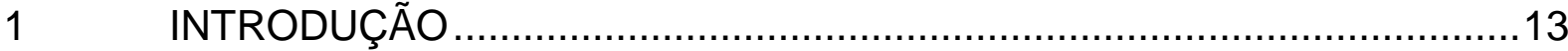

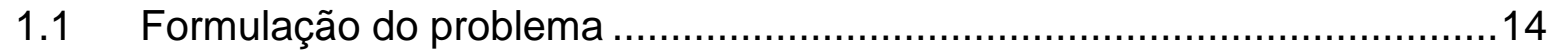

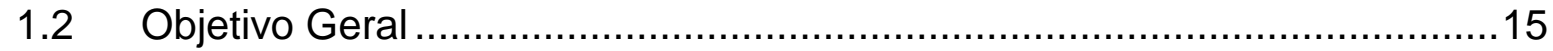

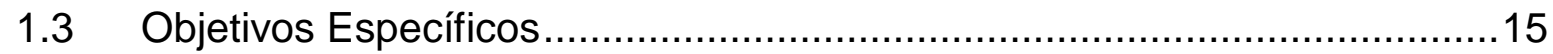

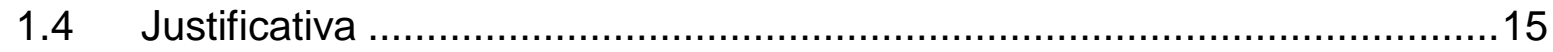

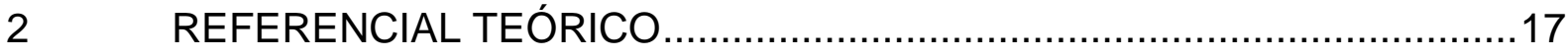

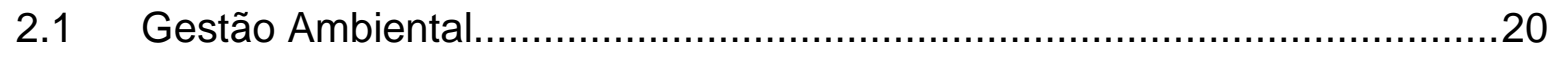

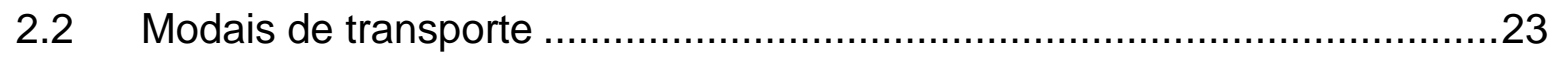

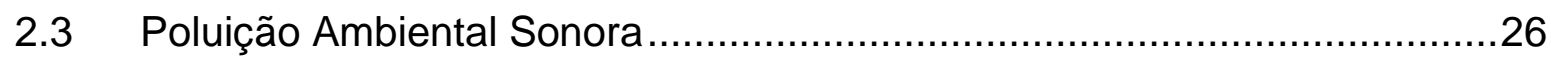

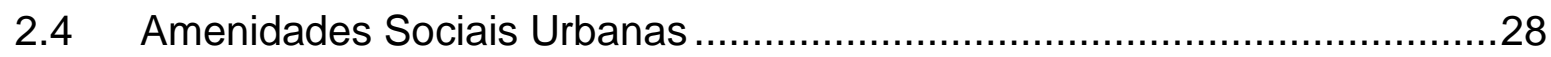

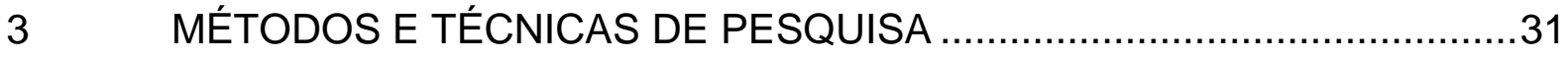

3.1 Tipo e descrição geral da pesquisa.........................................................

3.2 Caracterização da área do objeto de estudo ..........................................33

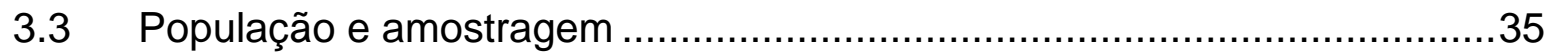

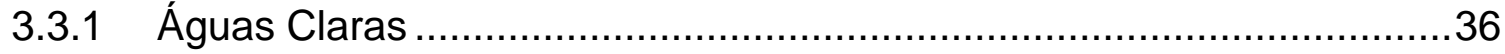

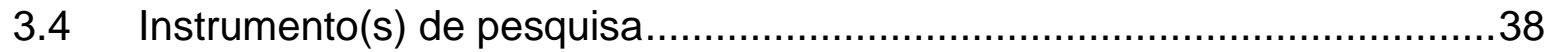

3.5 Procedimentos de coleta e de análise de dados.......................................40

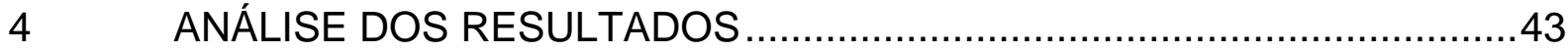

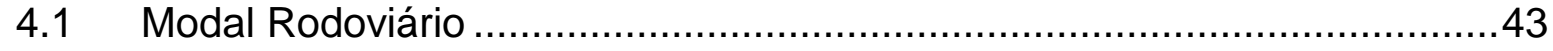

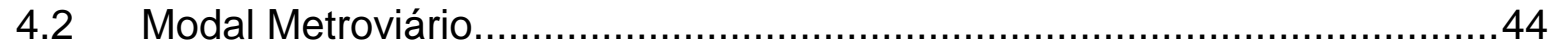

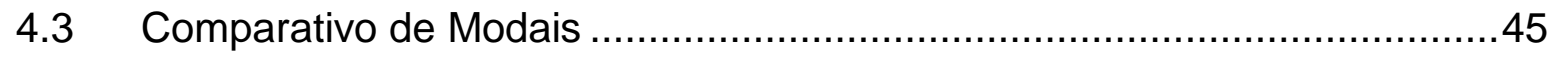

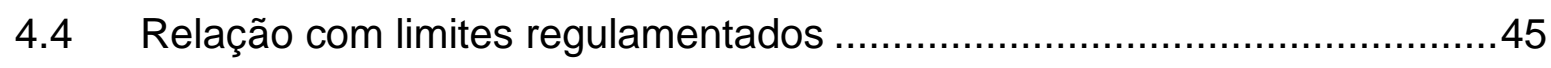

5 CONSIDERAÇÕES FINAIS Erro! Indicador não definido.

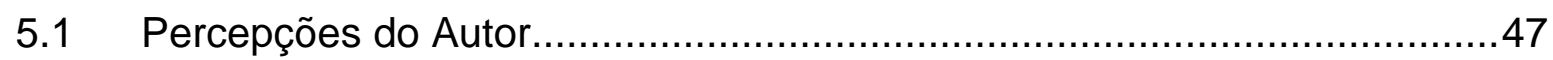

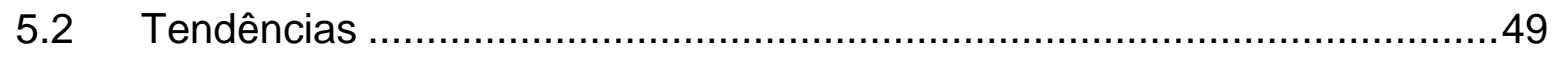

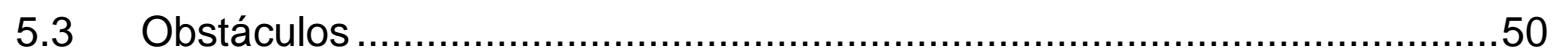




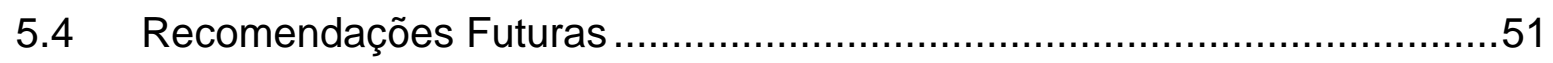

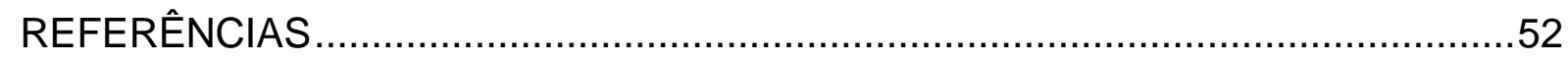

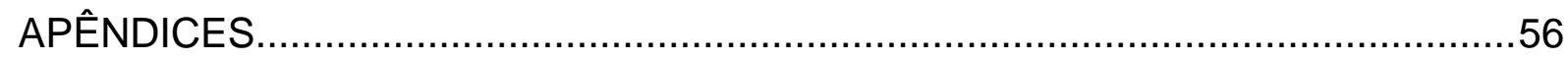

Apêndice A - Compilado de fotos das coletas de dados .................................56

Apêndice B - Tabulações de Dados de Coletas Rodoviário ...................................57

Apêndice C - Tabulações de Dados de Coletas Rodoviário ...................................58 


\section{INTRODUÇÃO}

É importante ressaltar, antes de qualquer coisa, a grande importância que a Gestão Ambiental tem ganhado dentro do aspecto organizacional e empresarial nos últimos anos. Em um passado não muito distante a gestão ambiental consistia praticamente em um sistema regulatório governamental, iniciado pela Organização das Nações Unidas em Estocolmo, na Suécia, em 1972.

Entretanto, as duas últimas décadas presenciaram avanços tecnológicos em um ritmo frenético, com isso as características dos mercados produtores e consumidores, das relações interpessoais, e principalmente da sociedade com o meio ambiente mudou de maneira vertiginosa, obrigando a população mundial a repensar toda a maneira de se relacionar com o meio o qual ocupa. Um dos componentes importantes dessa reviravolta nos modos de pensar e agir foi o crescimento da consciência ecológica, na sociedade, nos governos e nas próprias empresas. (TINOCO e ROBLES, 2006)

Dentro dessa nova realidade, o Brasil, por ser detentor da maior biodiversidade do planeta, segundo o Ministério do Meio Ambiente (2018), se encontra desempenhando um papel central nos debates sobre preservação ambiental, políticas de energia renovável e utilização da água. Além disso, por concentrar $60 \%$ de todo o território da floresta amazônica, o País é ainda mais pressionado por órgãos fiscalizadores e ONG's a se comprometer com a causa de preservação ambiental.

Apesar de ocupar grande parte da agenda de gestão ambiental, outros problemas vinculados ao meio ambiente também precisam de uma ação urgente por parte dos gestores e dos envolvidos em desenvolver uma melhor qualidade de vida à sociedade. Grande parte dos problemas são oriundos de um planejamento ambiental que não acompanhou o vertiginoso aumento populacional brasileiro e sua posterior ocupação do espaço demográfico.

A realidade do Distrito Federal no planejamento da ocupação do espaço, acompanha grande parte dos Estados Brasileiros, onde o aumento da população foi desordenado e não planejado. Segundo dados do IBGE (2018), nos últimos 50 anos, o país teve um aumento de 130 milhões de habitantes, e somente nos últimos 15 anos, 38 milhões. Ainda segundo o IBGE (2018) no Distrito Federal, o aumento foi 
de $18,2 \%$ de 2010 a 2017. Isso resulta em uma maior inoperância governamental em quesitos como saneamento básico, acesso a água potável e poluição do ar.

Dentro dessa perspectiva, Garbin (2013) expõe que o crescimento das cidades, quando exacerbado, vem a causar inevitavelmente, o excesso de ruídos. Esse problema se agrava em áreas de maior concentração de pessoas, e de fluxo de veículos automotores, como em grandes centros e áreas de rodagem de modais de transporte de passageiros, como ônibus, carros e metrô.

\subsection{Formulação do problema}

A resolução Conama $n^{\circ} 002$ de 1990 que instituiu o Programa Nacional de Educação e Controle da Poluição Sonora - intitulado Silêncio, que considera problemáticos os níveis excessivos de ruídos bem como a deterioração da qualidade de vida causada pela poluição.

São vários os problemas causados pela exposição a um nível de pressão sonora excessiva, segundo a Organização Mundial de Saúde (1999). Dentre eles:

- Perda auditiva temporária ou permanente;

- Fadiga;

- Perturbações do sono;

- Problemas cardiovasculares;

- Estresse;

- Distúrbios digestivos;

- Diminuição da concentração.

Levando tudo isso em consideração, é possível questionar:

Como está a poluição sonora oriunda de sistemas de transporte de passageiros ferroviário e rodoviário, a partir da comparação entre os modais e de cada modal com os parâmetros estabelecidos por lei ? 


\subsection{Objetivo Geral}

Analisar a poluição ambiental sonora dos sistemas de transporte de passageiros rodoviário e ferroviário e avaliar os possíveis impactos financeiros gerados por essa percepção.

\subsection{Objetivos Específicos}

Para alcançar o objetivo geral exposto anteriormente, é necessário estabelecer os objetivos abaixo especificados:

> Identificar os impactos gerados pela poluição sonora dos modais rodoviário e ferroviário;

$>$ Coletar dados que embasem o estudo;

Comparar os resultados de poluição sonora dos modais de transporte analisados; e

Interpretar os dados colhidos, descrevendo os impactos gerados pela poluição sonora.

\subsection{Justificativa}

A Organização Mundial da Saúde e o Banco Mundial classificam o ruído como um dos principais problemas ambientais à nível mundial, que pode causar danos fisiológicos ou psicológicos a um indivíduo. A poluição sonora é hoje, depois da poluição do ar e da água, o problema ambiental que afeta o maior número de pessoas.

O contexto populacional que norteia a ocupação das cidades, conforme já citado anteriormente nesse trabalho, é uma mudança irreversível, ou seja, não possui possibilidade de regressão. Entretanto, políticas de planejamento voltadas ao 
transporte de passageiros, podem minimizar os possíveis impactos gerados pela poluição sonora dos modais utilizados, além de sua localização e rotas.

A pesquisa é justificada, portanto, quando a união de fatores de saúde, já percebidos e sentidos pela população, vão de encontro com tendências de comportamento urbano, como a utilização de modais sonoramente poluentes, e a ocupação do espaço de maneira a intensificar os malefícios causados por esse tipo de poluição. 


\section{REFERENCIAL TEÓRICO}

O presente capítulo tem por objetivo embasar teoricamente os conceitos mais importantes e que serão de vital importância no andamento do trabalho. Gerando valor de informações que sejam o alicerce teórico para a investigação do problema apresentado, e sua consequente pesquisa e conclusão.

Para definir e facilitar o entendimento dos objetos da pesquisa, foi utilizado o método de Taxonomia de Bloom (1956) do Domínio Cognitivo. Tal metodologia é estruturada em níveis de complexidade crescente. De acordo Bloom (1956), são estabelecidos os seguintes níveis e verbos:

Conhecimento: refere-se à habilidade recordar, definir, reconhecer ou identificar informação específica, a partir de situações de aprendizagem anteriores;

Compreensão: refere-se à habilidade em demonstrar compreensão pela informação, sendo capaz de reproduzir a mesma por ideias e palavras próprias;

Aplicação: refere-se à habilidade em recolher e aplicar informação em situações ou problemas concretos;

Análise: refere-se à habilidade em estruturar informação, separando as partes das matérias de aprendizagem e estabelecer relações, explicando-as, entre as partes constituintes;

Síntese: refere-se à habilidade em recolher e relacionar informação de várias fontes, formando um produto novo;

Avaliação: refere-se à habilidade em fazer julgamentos sobre o valor de algo (produtos, ideias, etc.) tendo em consideração critérios conhecidos.

Visando um maior entendimento e compreensão das referências utilizadas, segue abaixo quadro com resumo de todas as definições e seus autores utilizados no referencial teórico.

Tabela 1 - Quadro de Taxonomia

\begin{tabular}{|c|c|c|}
\hline Termo & Conceito & Autor e Ano \\
\hline \multicolumn{3}{|c|}{ TÓPICO 2.1 - Gestão Ambiental } \\
\hline Gestão Ambiental & $\begin{array}{l}\text { Sistema que inclui estrutura, } \\
\text { atividade, práticas, responsabilidades }\end{array}$ & $\begin{array}{l}\text { Tinoco e Robles } \\
(2006)\end{array}$ \\
\hline
\end{tabular}




\begin{tabular}{|c|c|c|}
\hline & $\begin{array}{lcc}\text { e procedimentos visando } & \text { a } \\
\text { manutenção da política ambiental. }\end{array}$ & \\
\hline Preocupação Ambiental & $\begin{array}{l}\text { Acidentes } \mathrm{e} \text { Conferências } \\
\text { ambientais tiveram fator decisivo no } \\
\text { aumento da preocupação sobre a } \\
\text { questão ambiental. }\end{array}$ & $\begin{array}{l}\text { Campos e Melo } \\
(2008)\end{array}$ \\
\hline $\begin{array}{lc}\text { Sistema de } & \text { Gestão } \\
\text { Ambiental (SGA) } & \end{array}$ & $\begin{array}{l}\text { fornece a ordem e a consistência } \\
\text { necessária para uma organização } \\
\text { trabalhar suas preocupações } \\
\text { ambientais. }\end{array}$ & $\begin{array}{l}\text { Padoin, Junior e } \\
\text { Rosa (1998) }\end{array}$ \\
\hline Educação Ambiental & $\begin{array}{l}\text { Objetivos da Educação Ambiental, } \\
\text { tratados na Carta de Belgrado } \\
(1975)\end{array}$ & Barbieri (2011) \\
\hline $\begin{array}{l}\text { Gestão Ambiental na } \\
\text { esfera Privada }\end{array}$ & $\begin{array}{l}\text { Mudança da relação entre práticas } \\
\text { sustentáveis de obrigatórias para } \\
\text { voluntárias. }\end{array}$ & $\begin{array}{l}\text { Martins e Silva } \\
(2014)\end{array}$ \\
\hline $\begin{array}{lll}\text { Divisão da } & \text { Gestão } \\
\text { Ambiental } & & \end{array}$ & $\begin{array}{l}\text { Subdivisão do conceito de Gestão } \\
\text { Ambiental. }\end{array}$ & $\begin{array}{l}\text { Tinoco e Robles } \\
(2006)\end{array}$ \\
\hline $\begin{array}{l}\text { Gestão Ambiental na } \\
\text { esfera Pública }\end{array}$ & $\begin{array}{l}\text { Papel desempenhado pelo Governo } \\
\text { na aplicação da agenda ambiental. }\end{array}$ & Dambrós (2014) \\
\hline Resolução $n^{\circ} 02$ & $\begin{array}{l}\text { Dispõe sobre Programa Nacional de } \\
\text { Educação e Controle da Poluição } \\
\text { Sonora. }\end{array}$ & $\begin{array}{l}\text { CONAMA } \\
(1990)\end{array}$ \\
\hline \multicolumn{3}{|c|}{ TÓPICO 2.2 - Modais de Transporte } \\
\hline Tamanho da Frota & $\begin{array}{l}\text { Informa que na frota de carros no } \\
\text { DF alcançou a marca de } 1.700 .000 \\
\text { veículos. }\end{array}$ & DETRAN (2017) \\
\hline Importância Metrô & $\begin{array}{l}\text { O sistema de transporte metroviário } \\
\text { não só tem capacidade operacional } \\
\text { superior ao executado por ônibus, } \\
\text { mas também pode-se considerá-lo } \\
\text { mais confortável, confiável, veloz e } \\
\text { eficiente que o transporte rodoviário. }\end{array}$ & $\begin{array}{l}\text { Rodrigues } \\
(2003)\end{array}$ \\
\hline
\end{tabular}




\begin{tabular}{|c|c|c|}
\hline Modal mais utilizado & $\begin{array}{l}\text { Descreve a falta de qualidade do } \\
\text { transporte coletivo urbano como } \\
\text { uma das causas de tráfego nas } \\
\text { cidades grandes. }\end{array}$ & Amorim (2017) \\
\hline Trânsito & $\begin{array}{l}\text { Descreve a gravidade do problema } \\
\text { de trânsito em países europeus }\end{array}$ & $\begin{array}{l}\text { Araújo et al } \\
(2011)\end{array}$ \\
\hline \multicolumn{3}{|c|}{ TÓPICO 2.3 - Poluição Sonora } \\
\hline $\begin{array}{l}\text { Malefícios da Poluição } \\
\text { Sonora }\end{array}$ & $\begin{array}{l}\text { Enumera os malefícios que a } \\
\text { exposição a ruídos excessivos } \\
\text { podem causar. }\end{array}$ & $\begin{array}{l}\text { World Health } \\
\text { Organization }\end{array}$ \\
\hline Ruído & Som de caráter indesejável. & Costa (2011) \\
\hline Som x Ruído & 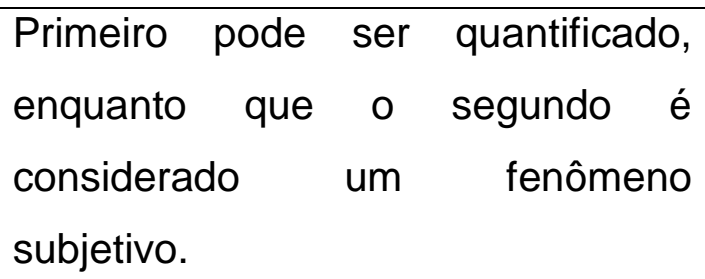 & Ganime (2010) \\
\hline $\begin{array}{l}\text { Extensão da Poluição } \\
\text { Sonora }\end{array}$ & $\begin{array}{l}\text { Exemplifica como o problema de } \\
\text { poluição sonora está presente na } \\
\text { sociedade atual. }\end{array}$ & Helmer (1995) \\
\hline Ruído Urbano & $\begin{array}{l}\text { Soma resultante de um conjunto de } \\
\text { ruídos sonoros oriundos de diversas } \\
\text { fontes num determinado espaço } \\
\text { geográfico. }\end{array}$ & $\begin{array}{l}\text { Silva, Silva e } \\
\text { Souza (2011) }\end{array}$ \\
\hline $\begin{array}{l}\text { Malefícios do Ruído } \\
\text { Urbano }\end{array}$ & $\begin{array}{l}\text { Cerca de } 50 \text { mil pessoas morrem } \\
\text { por ano na União Europeia (UE) } \\
\text { devido a ataques cardíacos } \\
\text { causados pelo excesso de ruído } \\
\text { rodoviário e ferroviário }\end{array}$ & $\begin{array}{l}\text { Transport \& } \\
\text { Environment } \\
(2008)\end{array}$ \\
\hline Lei $n^{\circ} 6.938 / 81$ & $\begin{array}{l}\text { Responsável por instituir a Política } \\
\text { Nacional do Meio Ambiente }\end{array}$ & $\begin{array}{l}\text { Constituição } \\
\text { Federal (1981) }\end{array}$ \\
\hline \multicolumn{3}{|c|}{ TÓPICO 2.4 - Amenidades Sociais Urbanas } \\
\hline $\begin{array}{l}\text { Desenvolvimento } \\
\text { Geográfico }\end{array}$ & $\begin{array}{l}\text { Explica que melhorar a } \\
\text { infraestrutura de determinado } \\
\text { espaço, melhora também os meios }\end{array}$ & Reitveld (1989) \\
\hline
\end{tabular}




\begin{tabular}{|c|c|c|}
\hline & de produção naquele local. & \\
\hline $\begin{array}{l}\text { Fatores de escolha } \\
\text { demográfica }\end{array}$ & $\begin{array}{l}\text { Fatores de } \\
\text { microeconômicos, oscolha } \\
\text { consumidor é levado a escolher } \\
\text { conforme o aumento do seu bem } \\
\text { estar. }\end{array}$ & $\begin{array}{l}\text { Rocha e } \\
\text { Magalhães } \\
(2013)\end{array}$ \\
\hline $\begin{array}{l}\text { Classificação de uma } \\
\text { habitação }\end{array}$ & $\begin{array}{l}\text { Elenca os fatores que são } \\
\text { necessários para que uma } \\
\text { habitação seja considerada apta a } \\
\text { abrigar pessoas, incluindo aí a } \\
\text { ausência de barulho. }\end{array}$ & $\begin{array}{l}\text { Goromosov } \\
(1968)\end{array}$ \\
\hline
\end{tabular}

\subsection{Gestão Ambiental}

Segundo Tinoco e Robles (2006) Gestão Ambiental consiste em um sistema que inclui a estrutura organizacional, atividades de planejamento, responsabilidades, práticas, procedimentos, processos e recursos para desenvolver, implementar, atingir, analisar criticamente e manter a política ambiental.

Outros fatores como legislação, certificados e normas possuem vital importância na consolidação da Gestão Ambiental, que é composta por:

Política Ambiental: conjunto de princípios doutrinários que conformam as aspirações sociais e/ou governamentais quanto à regulação do uso, controle, proteção e conservação do ambiente.

Planejamento Ambiental: estudo prospectivo que visa atender a Política Ambiental, através da coordenação, compatibilização, articulação e implantação de projetos de intervenção estruturais e não estruturais.

Gerenciamento ambiental: conjunto de ações para regular na prática operacional o uso, controle, proteção e conservação do ambiente, verificando sua conformidade coma Política Ambiental.

Métodos de Gerenciamento Ambiental: estabelecimento de referencial teórico para a participação dos diferentes agentes envolvidos no Gerenciamento. 
Sistema de Gerenciamento Ambiental: conjunto de organismos, agências e instituições governamentais e privadas, estabelecido para executar a Política Ambiental.

De acordo com Campos e Melo (2008) os acidentes ambientais e as conferências internacionais tiveram fator decisivo no desenvolvimento de uma nova consciência ambiental e para o aumento da pressão da opinião pública e dos órgãos reguladores sobre as empresas, emergindo uma maior preocupação das empresas em dar uma atenção especial à questão ambiental.

Na esfera de gestão privada, é perceptível a mudança de realidade dentro das empresas, no que tange a obrigatoriedade de práticas que sejam revertidas em benefícios ambientais. Se há alguns anos essas práticas eram encaradas como formalidade mediante imposições jurídicas e normativas, hoje já passam a ser de natureza voluntária.

A utilização de um Sistema de Gestão Ambiental (SGA), segundo Raful (2010), já é encarado, por exemplo, como um diferencial competitivo de mercado, sendo esse sistema responsável direto por redução de custos.

Padoin, Junior e Rosa (1998) destacam que um SGA consegue fornecer a ordem e a consistência necessária para uma organização trabalhar suas preocupações ambientais, mediante alocação de recursos, atribuição de responsabilidade, e avaliação contínua de suas práticas, procedimentos e processos.

Segundo Martins e Silva (2014) a compreensão dessa mudança de paradigma é uma questão de manutenção da competitividade, uma vez que o mercado está, a cada dia, mais aberto e competitivo, fazendo com que as empresas tenham que se preocupar com o controle dos impactos ambientais.

Partindo dessa definição Tinoco (2006) divide a Gestão Ambiental conforme tabela abaixo: 
Tabela 2 - Divisão da Gestão Ambiental

\begin{tabular}{|c|c|c|c|}
\hline $\begin{array}{l}\text { Gestão de } \\
\text { processos }\end{array}$ & $\begin{array}{l}\text { Gestão de } \\
\text { resultados }\end{array}$ & $\begin{array}{c}\text { Gestão de } \\
\text { sustentabilidade }\end{array}$ & $\begin{array}{c}\text { Gestão de plano } \\
\text { ambiental }\end{array}$ \\
\hline Exploração de recursos & Emissões gasosas & Qualidade do ar & Políticas e compromisso \\
\hline $\begin{array}{l}\text { Transformação de } \\
\text { recursos }\end{array}$ & Efluentes líquidos & Qualidade da água & Política ambiental \\
\hline $\begin{array}{l}\text { Acondicionamento de } \\
\text { recursos }\end{array}$ & Resíduos sólidos & Qualidade dos solos & Conformidade legal \\
\hline Transporte de recursos & Particulados & $\begin{array}{l}\text { Abundancia e diversidade } \\
\text { da flora }\end{array}$ & Objetivos e metas \\
\hline $\begin{array}{l}\text { Aplicação e uso de } \\
\text { recursos }\end{array}$ & Odores & $\begin{array}{l}\text { Abundância e diversidade } \\
\text { da fauna }\end{array}$ & Programa ambiental \\
\hline $\begin{array}{l}\text { Quadro de riscos } \\
\text { ambientais }\end{array}$ & Ruídos e vibrações & $\begin{array}{l}\text { Qualidade de vida do ser } \\
\text { humano }\end{array}$ & Projetos ambientais \\
\hline Situação de emergência & Iluminação & Imagem institucional & $\begin{array}{l}\text { Ações corretivas e } \\
\text { preventivas }\end{array}$ \\
\hline
\end{tabular}

Fonte: Tinoco (2006)

A busca por um desenvolvimento econômico e social sustentável, apesar de ter ganhado uma enorme preponderância nos últimos anos, já era motivo de preocupação desde antes de 1972, quando foi realizada a Conferência de Estocolmo, tendo como pauta o Meio Ambiente. Barbieri (2011) elenca os objetivos da educação ambiental tratada na Carta de Belgrado, conforme abaixo:

Conscientização: contribuir para que indivíduos e grupos adquiram consciência e sensibilidade em relação ao meio ambiente como um todo e quanto aos problemas relacionados com ele.

Conhecimento: propiciar uma compreensão básica sobre o meio ambiente, principalmente quanto às influências do ser humano e de suas atividades.

Atitudes: propiciar a aquisição de valores e motivação para induzir uma participação ativa na proteção ao meio ambiente e na resolução dos problemas ambientais.

Habilidades: proporcionar condições para que os indivíduos e grupos sociais adquiram as habilidades necessárias a essa participação ativa.

Capacidade de avaliação: estimular a avaliação das providências efetivamente tomadas em relação ao meio ambiente e aos programas de educação ambiental.

Participação: contribuir para que os indivíduos e grupos desenvolvam o senso de responsabilidade e de urgência com relação às questões ambientais. 
Dentro dessas questões de Educação Ambiental, podemos entender melhor o conceito de Gestão Ambiental, que de maneira geral consiste no estudo da administração do exercício de atividades econômicas e sociais de forma a utilizar de maneira racional os recursos naturais, visando à sustentabilidade, estando presente em todas as esferas de gestão, seja ela pública, privada, governamental e social.

A composição da Gestão Ambiental é claramente vista dentro da esfera pública, levando-se em consideração que a agenda ambiental é quase que em sua totalidade de responsabilidade governamental. Nesse sentido, Dambrós (2014) descreve que, o Poder Público pode ser definido como o detentor de poderes e obrigações estabelecidos na legislação, que lhe permitem promover desde o ordenamento e controle do uso dos recursos ambientais (incluindo a criação de incentivos fiscais na área ambiental) até a reparação e a prisão de indivíduos pelo dano ambiental.

Esse cenário reforça o papel central do Estado na defesa dos interesses ambientais perante situações que desfavoreçam o desenvolvimento sustentável. Fato esse que coloca o Ministério do Meio Ambiente como mediador de assuntos com as demais esferas da sociedade no que tange a gestão ambiental nacional. No que tange especificamente o presente trabalho, é possível citar, por exemplo, a Resolução CONAMA n 2, de 8 de março de 1990 que dispõe sobre o Programa Nacional de Educação e Controle da Poluição Sonora.

\subsection{Modais de transporte}

Dados do DETRAN (2017) informaram que a frota de veículos do Distrito Federal alcançou a marca de 1.700 .000 veículos. Esse dado coloca Brasília em $4^{\circ}$ no ranking de frotas de veículos no Brasil, perdendo apenas para grandes capitais como São Paulo, Rio de Janeiro e Belo Horizonte.

Esse dado escancara algumas características da circulação de pessoas no DF como a falta de transporte público de qualidade, a pouca abrangência do Metrô, perante o tamanho do território do DF, além da malha rodoviária, que em sua maioria é composta por vias expressas largas e de velocidade moderada/alta. 
Quando se fala em abrangência do metrô, é perceptível pelo mapa abaixo, que somente um "lado" do DF é contemplado por esse meio de transporte público, enquanto o outro ainda carece desse serviço.

Um grande agravante é o fato de a Asa Norte ainda não ter sido alcançada pelo metrô, pois nessa localidade se encontram centros empresarias, universidades, polos comercias e órgão da administração pública. Outro fator alarmante consiste no fato de que no projeto inicial, as duas Asas do Plano Piloto seriam contempladas, fato que acabou não se concretizando, deixando milhares de usuários sem alternativas de locomoção.

Figura 1 - Mapa Metrô DF

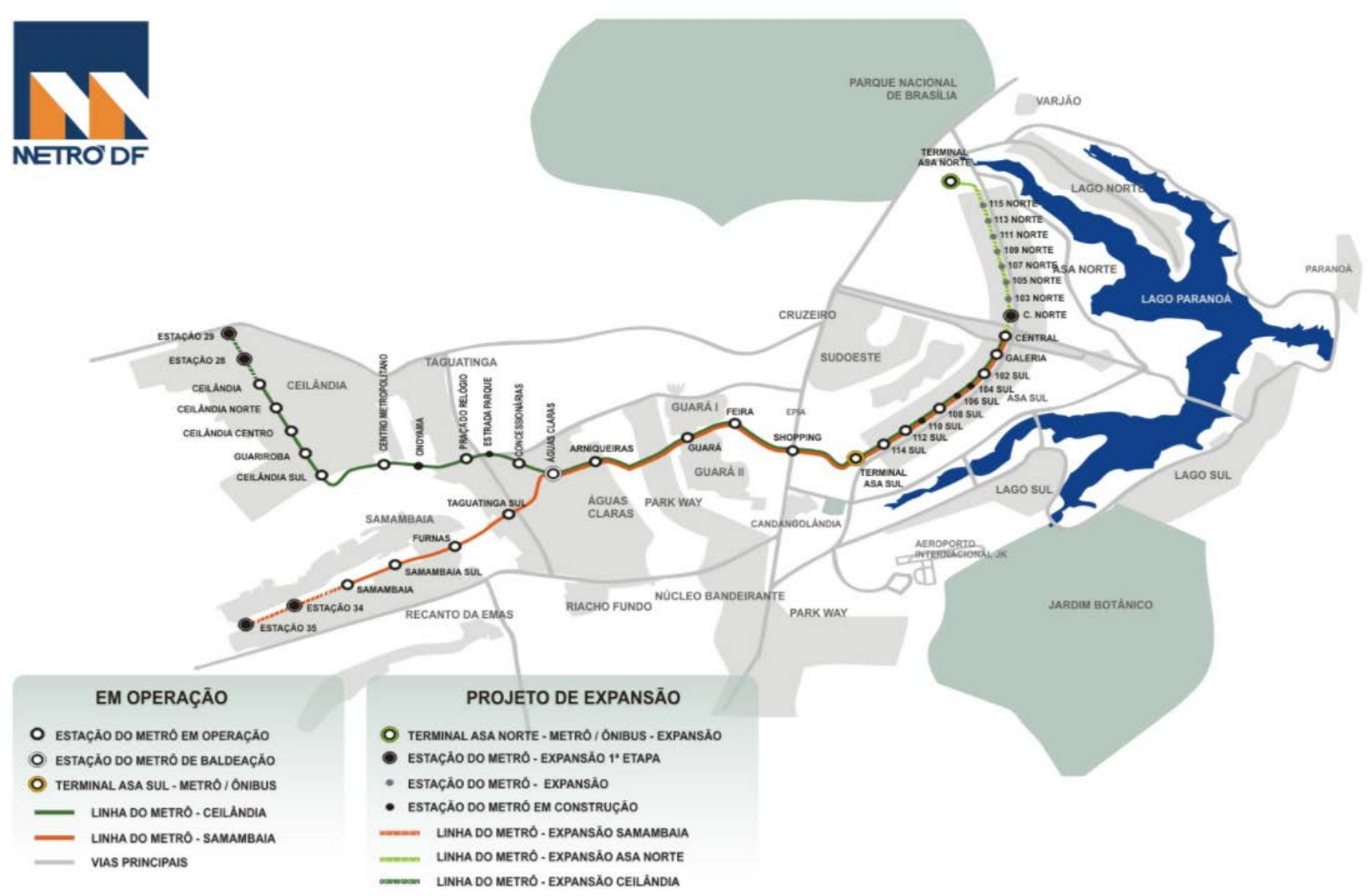

Fonte: Metrô DF (2018)

Segundo Rodrigues (2003) o sistema de transporte metroviário tem participação vital na mobilidade do DF, pois, não só tem capacidade operacional superior ao executado por ônibus, mas também pode-se considerá-lo mais confortável, confiável, veloz e eficiente que o transporte rodoviário.

Outro fator que deve ser levado em consideração nos modais de transporte do DF é a grande distância percorrida pelos residentes das Regiões Administrativas, e que precisam se locomover até o centro de Brasília, que é restrito a uma minoria da 
população residente do DF. Abaixo é possível ver a evolução da frota de veículos de 2000 a 2011, e um comparativo entre o crescimento da frota de veículos e a população residente no DF.

Tabela 3 - Evolução Frota de Veículos

\begin{tabular}{|c|c|c|c|}
\hline Ano & Frota & Diferença & Variação(\%) \\
\hline 2000 & 585.424 & & \\
\hline 2001 & 651.342 & 65.918 & 11,3 \\
\hline 2002 & 688.746 & 37.404 & 5,7 \\
\hline 2003 & 732.138 & 43.392 & 6,3 \\
\hline 2004 & 775.112 & 42.974 & 5,9 \\
\hline 2005 & 821.352 & 46.240 & 6,0 \\
\hline 2006 & 883.676 & 62.324 & 7,6 \\
\hline 2007 & 964.534 & 80.858 & 9,2 \\
\hline 2008 & 1.046 .638 & 82.104 & 8,5 \\
\hline 2009 & 1.138 .127 & 91.489 & 8,7 \\
\hline 2010 & 1.233 .000 & 94.873 & 8,3 \\
\hline 2011 & 1.317 .721 & 84.721 & 6,9 \\
\hline
\end{tabular}

Fonte: (DETRAN, 2012)

Tabela 4 - Comparativo entre carros e residentes no DF

\begin{tabular}{|c|c|c|c|}
\hline Ano & $\mathbf{2 0 0 0}$ & $\mathbf{2 0 1 0}$ & Variação(\%) \\
\hline População & 2.051 .146 & 2.562 .693 & 25,0 \\
\hline Frota de veículos & 585.424 & 1.233 .000 & 110,6 \\
\hline
\end{tabular}

Fonte: (DETRAN, 2012)

Segundo Amorim (2017) Os ônibus são o modal de transporte coletivo predominante no Brasil. Devido à baixa qualidade dos serviços ofertados, esse sistema é pouco atrativo, sendo um dos fatores que contribuem para o elevado número de veículos leves circulantes, que trafegam em situação de baixa densidade de ocupação veicular.

Perante as dificuldades encontradas no transporte público, muitas pessoas recorrem a um meio de transporte particular, gerando outro grande problema das cidades grandes, o trânsito. A definição de trânsito consiste na utilização das vias por veículos motorizados, veículos não motorizados, pedestres e animais de tração, para fins de circulação, parada passageira ou estacionamento. Araújo et al (2011) 
ressalta que em muitos países, tamanho é seu impacto na qualidade de vida das pessoas, o trânsito é enquadrado como um problema ambiental e de saúde pública.

Villavencio (2006) especifica ainda que a insegurança e o desconforto típicos do transporte público são outros fatores a serem levados em consideração na hora em que o cidadão escolhe seu meio de transporte. Fato esse que agrava ainda mais todos os problemas listados anteriormente

\subsection{Poluição Ambiental Sonora}

Segundo a World Health Organization (WHO), ruídos excessivos interferem nas atividades cotidianas das pessoas, sejam elas no trabalho, nas escolas e até mesmo em casa e em atividades que visam o lazer. Podem causar perturbações no sono, danos cardiovasculares, distúrbios psicológicos, além de reduzir o desempenho em atividades corriqueiras.

Para melhor entender o alarmante resultado da WHO, é preciso definir ruído, que segundo Costa (2011) pode ser conceituado como um som de caráter indesejável, que por vezes pode causar danos à saúde do ser humano.

Portanto, som e ruído, são classificados de maneira distinta pela ciência, uma vez que, segundo Ganime (2010) sabe-se que o primeiro pode ser quantificado, enquanto que o segundo é considerado um fenômeno subjetivo. Ou seja, o incômodo dos ruídos podem ter efeitos diferentes de acordo com a tolerância e a percepção do mesmo.

Dentre os tipos de ruídos, o especificado nesse trabalho pode ser classificado como ao ruído urbano. Silva, Silva e Souza (2011) caracterizam o ruído urbano como a soma resultante de um conjunto de ruídos sonoros oriundos de diversas fontes num determinado espaço geográfico, tais como: atividades industriais, obras de construção civil, alarmes, tráfego aéreo, ferroviário e rodoviário, vizinhança, construções religiosas, bares e restaurantes.

De acordo com Helmer (1995) a extensão do problema de poluição sonora é grande. Nos países da União Europeia, 40\% da população está exposta a níveis 
sonoros maiores do que $55 \mathrm{~dB}(\mathrm{~A})$ e $20 \%$ está exposta a níveis mais elevados do que $65 \mathrm{~dB}(\mathrm{~A})$. Grande parte desses ruídos são originados em rodovias onde, segundo dados captados na Europa a pressão sonora varia entre 75 - $80 \mathrm{~dB}(\mathrm{~A}) 24$ horas por dia.

Juridicamente, a Lei $\mathrm{n}^{\circ}$ 6.938/81, responsável por instituir a Política Nacional do Meio Ambiente, em seu art. $3^{\circ}$, inciso III, define a poluição como a degradação da qualidade ambiental resultante de atividades que direta ou indiretamente: prejudiquem a saúde, criem condições adversas às atividades sociais e econômicas, afetem desfavoravelmente a biota, afetem as condições estéticas ou sanitárias do meio ambiente, lancem matérias ou energia em desacordo com os padrões ambientais estabelecidos.

Além disso o Superior Tribunal de Justiça - STJ (2013) considera que a poluição sonora é um tipo penal previsto na Lei de Crimes Ambientais (Lei 9.605/98), e assim tem agido em seus julgamentos.

Define-se, portanto, a poluição sonora como a degradação da qualidade ambiental - fruto de som puro ou da conjugação de sons. As atividades sonoras serão consideradas poluidoras por presunção legal, na medida em que se situarem fora dos padrões admitidos em lei, nas resoluções do CONAMA e nas normas técnicas recomendadas.

Dados preliminares do Environmental Burden of Disease (EBD), revelaram que nos 6 países pesquisados pela OMS, o barulho do tráfego é o motivo de maior estresse urbano. Apesar disso, foi exposto pelo mesmo estudo que apesar de grave, esse tipo de poluição tem diminuído, perante outros tipos de poluição.

Dados apresentados pela Transport \& Environment (2008) revelaram ainda, em Bruxelas, que cerca de 50 mil pessoas morrem por ano na União Europeia (UE) devido a ataques cardíacos causados pelo excesso de ruído rodoviário e ferroviário, e que 200 mil passam a sofrer anualmente de doenças do coração.

Segundo pesquisas realizadas pelo MPT (2017) cerca de 48\% dos rodoviários são vítimas de Perda Auditiva Induzida por Ruído (PAIR). O que levou o Governo do Distrito Federal a estudar a modernização da frota rodoviária. 
A Associação Brasileira de Normas Técnicas - ABNT, define, em sua NBR $n^{\circ}$ 10151, de junho de 2000, os limites de emissão de ruídos:

Tabela 5 - Nível de critério de avaliação NCA para ambientes externos, em dB(A)

\begin{tabular}{|l|c|c|}
\hline \multicolumn{1}{|c|}{ Tipos de áreas } & Diurno & Noturno \\
\hline Áreas de sítios e fazenda & 40 & 35 \\
\hline Área estritamente residencial urbana ou de hospitais ou de & 50 & 45 \\
escolas & & \\
\hline Área mista, predominantemente residencial & 55 & 50 \\
\hline Área mista, com vocação comercial e administrativa & 60 & 55 \\
\hline Área mista, com vocação recreacional & 65 & 55 \\
\hline Área predominantemente industrial & 70 & 60 \\
\hline
\end{tabular}

Fonte: ABNT (2000)

\subsection{Amenidades Sociais Urbanas}

Mensurar a qualidade de vida da população de determinado espaço geográfico é um desafio enfrentado por vários órgãos a nível mundial. Dos resultados obtidos é possível estabelecer políticas públicas que visem a diminuição da desigualdade de renda, além de um aumento da qualidade de vida, longevidade e taxa de alfabetização.

O PNUD - Programa das Nações Unidas para o Desenvolvimento é responsável por medir, e gerar relatórios de posicionamento dos países de acordo com seus respectivos desenvolvimentos em saúde, educação e renda. No último censo, medido pelo PNUD, o Brasil foi alocado na $75^{\circ}$ posição, em um total de 188 , com um IDH de 0,755 , que, segundo critérios da Instituição, o caracteriza como um País de Alto Desenvolvimento Humano. 
Tabela 6 - Ranking IDH

\begin{tabular}{|c|c|c|}
\hline Ranking IDH Global & País & IDH 2014 \\
\hline $1^{\circ}$ & Noruega & 0,944 \\
\hline $2^{\circ}$ & Austrália & 0,935 \\
\hline $3^{\circ}$ & Suíça & 0,930 \\
\hline $4^{\circ}$ & Dinamarca & 0,923 \\
\hline $74^{\circ}$ & México & 0,756 \\
\hline $75^{\circ}$ & Brasil & 0,755 \\
\hline $76^{\circ}$ & Geórgia & 0,754 \\
\hline
\end{tabular}

Fonte: Relatório de Desenvolvimento Humano (2015)

Segundo a própria ONU, o RDH - Relatório de Desenvolvimento Humano tem um grande impacto nas reflexões sobre o tema no mundo todo, pois abordam questões que colocam as pessoas no centro das estratégias de enfrentamento aos desafios do desenvolvimento.

Aplicando uma lupa no espectro analisado, podemos analisar o IDH dos municípios, cujo último censo foi medido em 2010 e as 10 primeiras cidades podem ser vistas na tabela abaixo:

Tabela 7 - IDH Municípios

\begin{tabular}{|c|c|c|c|c|c|}
\hline $\begin{array}{c}\text { Ranking } \\
\text { IDHM } \\
\mathbf{2 0 1 0}\end{array}$ & Município & $\begin{array}{c}\text { IDHM } \\
\mathbf{2 0 1 0}\end{array}$ & $\begin{array}{c}\text { IDHM } \\
\text { Renda } \\
\mathbf{2 0 1 0}\end{array}$ & $\begin{array}{c}\text { IDHM } \\
\text { Longevidade } \\
\mathbf{2 0 1 0}\end{array}$ & $\begin{array}{c}\text { IDHM } \\
\text { Educação } \\
\mathbf{2 0 1 0}\end{array}$ \\
\hline $1^{\circ}$ & São Caetano do Sul (SP) & 0,862 & 0,891 & 0,887 & 0,811 \\
\hline $2^{\circ}$ & Águas de São Pedro (SP) & 0,854 & 0,849 & 0,890 & 0,825 \\
\hline $3^{\circ}$ & Florianópolis (SC) & 0,847 & 0,870 & 0,873 & 0,800 \\
\hline $4^{\circ}$ & Balneário Camboriú (SC) & 0,845 & 0,854 & 0,894 & 0,789 \\
\hline $5^{\circ}$ & Vitória (ES) & 0,845 & 0,876 & 0,855 & 0,805 \\
\hline $6^{\circ}$ & Santos (SP) & 0,840 & 0,861 & 0,852 & 0,807 \\
\hline $7^{\circ}$ & Niterói (RJ) & 0,837 & 0,887 & 0,854 & 0,773 \\
\hline $8^{\circ}$ & Joaçaba (SC) & 0,827 & 0,823 & 0,891 & 0,771 \\
\hline $9^{\circ}$ & Brasília (DF) & 0,824 & 0,863 & 0,873 & 0,742 \\
\hline $10^{\circ}$ & Curitiba (PR) & 0,823 & 0,850 & 0,855 & 0,768 \\
\hline
\end{tabular}

Fonte: PNUD Brasil (2010) 
Segundo Reitveld (1989), o desenvolvimento de determinada região não é resultado somente de fatores privados de produção, como investimento financeiro e trabalho, mas também de desenvolvimento estrutural. Melhorar a infraestrutura significa aumentar a produtividade e os fatores de produção privados. A partir disso é possível estabelecer um paralelo entre investimento governamental e o aumento das taxas produtivas oriundas de espaços demográficos que recebam tais investimentos. Transporte público de qualidade e abrangência, segurança e saneamento básico, são exemplos de melhoras estruturais que podem resultar em aumento das taxas de produção.

Dentro da realidade de um país com dimensões continentais, é natural que existam características climáticas, econômicas, sociais e geográficas que gerem aglomerações maiores ou menores, de acordo com o benefício que essas especificidades gerem para os habitantes de determinado centro. Partindo desse princípio, Rocha e Magalhães (2013) demonstram que é intuitivo supor que os trabalhadores, ao fazerem uma escolha locacional levem em consideração tanto as oportunidades econômicas ofertadas por cada região quanto os demais fatores não econômicos que influenciam a sua função de bem-estar.

O conceito de bem-estar, no geral, engloba o sentimento de satisfação e felicidade. Porém, algumas vertentes associam essa condição ao estado de pessoas que no quesito econômico, ocupam uma posição favorável, possuindo um conforto de vida que exponha essa sensação de felicidade. Essa relação de bem-estar com poderio econômico é evidenciada, por exemplo, nos locais de habitação das pessoas de acordo com sua posição social, onde por força de mercado, as habitações mais bem estruturadas são financeiramente mais elevadas do que as que possuem menos infraestrutura.

Goromosov (1968) classifica uma habitação como saudável, caso a mesma atenda as seguintes necessidades: temperatura adequada, ar interior puro, iluminação natural e artificial, bem estar acústico e projeto adequado. É perceptível, portanto que uma das principais funções de uma residência, ainda hoje, é de prover descanso, e os ruídos são consequentemente, um obstáculo ao alcance desse objetivo. 


\section{MÉTODOS E TÉCNICAS DE PESQUISA}

Posteriormente às pesquisas bibliográficas, às consultas aos dados disponíveis, documentos e legislações vigentes, em âmbito Federal e Distrital, foi feita uma pesquisa de natureza quantitativa e cunho exploratório, por meio de coleta de dados em campo, seguindo conjunto de parâmetros estabelecidos por este capítulo e pelas normas que norteiam o tema em questão.

\subsection{Tipo e descrição geral da pesquisa}

Conforme Ciribelli (2003) o método científico pode ser definido como um conjunto de etapas e instrumentos pelo quais o pesquisador direciona seu projeto de trabalho com critérios de caráter científico o presente estudo possui como alicerces principais 3 pilares de embasamento, que consistem em:

Revisão bibliográfica: engloba o referencial teórico, onde foram buscados artigos, trechos de livros, dissertações, além de periódicos e cartilhas que pudessem dar robustez ao tema abordado no trabalho.

Regulamentações: por se tratar de um trabalho voltado à problemática da sustentabilidade, foi feita uma exaustiva busca por legislações dos mais diversos âmbitos, além de recomendações de órgãos especializados localizados no mundo inteiro, uma vez que o problema é de caráter global. A exemplificar a NBR 1051, que fixa as condições exigíveis para avaliação da aceitabilidade do ruído em comunidades. Especifica de maneira objetiva uma metodologia para a medição do ruído e estabelece um critério de comparação que considera diversos fatores ambientais e de localidade.

Trabalho em campo: de maneira a complementar toda a esfera documental presente no estudo, foi realizada ainda uma coleta de dados em campo, onde foram mensurados dados quantitativos que disponibilizassem insumo para a análise da problemática.

Gil (2002) determina que qualquer classificação deve ser feita mediante objetivos. Com relação as pesquisas, usualmente são classificadas de acordo com seus objetivos gerais. Sendo assim, é possível classificar uma pesquisa de acordo 
com sua finalidade, seus métodos particulares, sua área de conhecimento e até o seu nível de explicação.

Portanto, o nível de classificação de uma pesquisa está diretamente ligado ao seu método de abordagem do problema, à sua natureza e também pelo ponto de vista dos procedimentos técnicos utilizados durante a elaboração do trabalho.

De acordo com a finalidade da pesquisa, conforme Gil (2010), a presente se enquadra como Aplicada, uma vez que sua aplicação se dá ao longo do trabalho, de acordo com as descobertas, para que seja completa. Além disso está mais concentrada na aplicação, nas consequências e na utilização dos conhecimentos descobertos, do que no desenvolvimento de ideias universais propriamente ditas.

Com relação ao nível da Pesquisa, para Duverger (1962), a pesquisa atual é exploratória, pois possui, como principal finalidade desenvolver e esclarecer, por meio de exploração teórica, conceitos e ideias e, após isso, corroborar a pesquisa por meio de aferições no campo.

Levando em consideração o procedimento que sustentou as análises por meio da coleta de dados, o mesmo foi o estudo de campo, que segundo Gil (2010) procuram se aprofundar em questões propostas, que propriamente na característica da população, segundo variáveis pré definidas.

Por esse motivo o planejamento do estudo de campo se torna muito mais flexível, mesmo que a pesquisa passe por processos de reformulação durante a elaboração.

Portanto, a presente pesquisa, se caracteriza como de finalidade aplicada, de nível exploratório que contém um experimento de coleta de dados quantitativos e que faz uso também da subjetividade de dados de cunho qualitativo para estimar tendências de comportamento além de políticas públicas nos âmbitos ambientais e econômicos que corroborem ou não com a realidade do contexto demográfico, político e social da pesquisa. 


\subsection{Caracterização da área do objeto de estudo}

O presente trabalho foi desenvolvido com base em medições realizadas na Região Centro Oeste do Brasil, mais precisamente na Região Administrativa de Águas Claras, no Distrito Federal. O DF é uma das 27 Unidades da Federação, sendo a menor entre todas elas. Diferentemente dos estados do país, Brasília não é dividida em cidades e bairros, portanto não há prefeituras. A capital é composta por 31 Regiões Administrativas (RA's) oficialmente constituídas como dependentes do Governo de Brasília.

Figura 2 - Mapa do Brasil

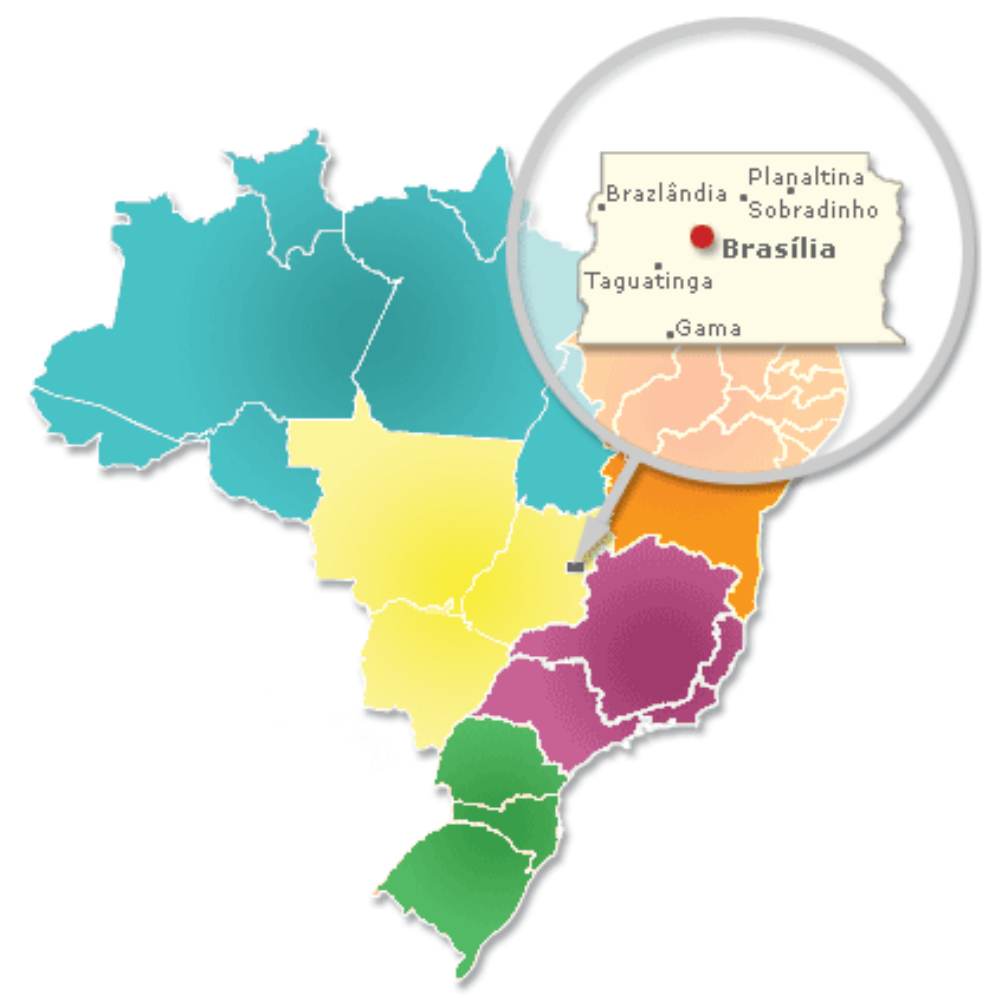

Fonte: Google (2018)

Brasília se caracteriza como a capital do Governo Federal, e também a sede do Governo do Distrito Federal. A cidade está localizada a $15^{\circ} 47^{\prime}$ de latitude sul e a $47^{\circ} 56^{\prime}$ de longitude oeste. Está a cerca de 1.000 metros do nível do mar e tem relevo predominantemente plano. O ponto mais alto é o Pico do Roncador, com 1.341 metros. Além disso, possui temperatura média de $22^{\circ} \mathrm{C}$ e variações que vão de $13^{\circ} \mathrm{C}$ a $28^{\circ} \mathrm{C}$ ao longo do ano, se considerada a média dos últimos 30 anos. 
Por se encontrar no centro político do país, a realidade econômica do DF é particular em relação ao restante do território brasileiro. Esse fato acaba por ser refletido na sociedade que habita essa pequena parte do Centro-Oeste. Focada quase que integralmente no funcionalismo público, Brasília se tornou refrência em índices econômicos e de desenvolvimento, grande parte devido aos altos salários que as carreiras públicas tendem a pagar. Além disso, boa parte da indústria de consumo também se solidificou em volta do aparato público, sendo grande a quantidade de Licitações e Contratos de grande valor financeiro que percorrem os corredores das empresas prestadoras de serviço no Distrito Federal.

Figura 3 - IDH Brasil x DF

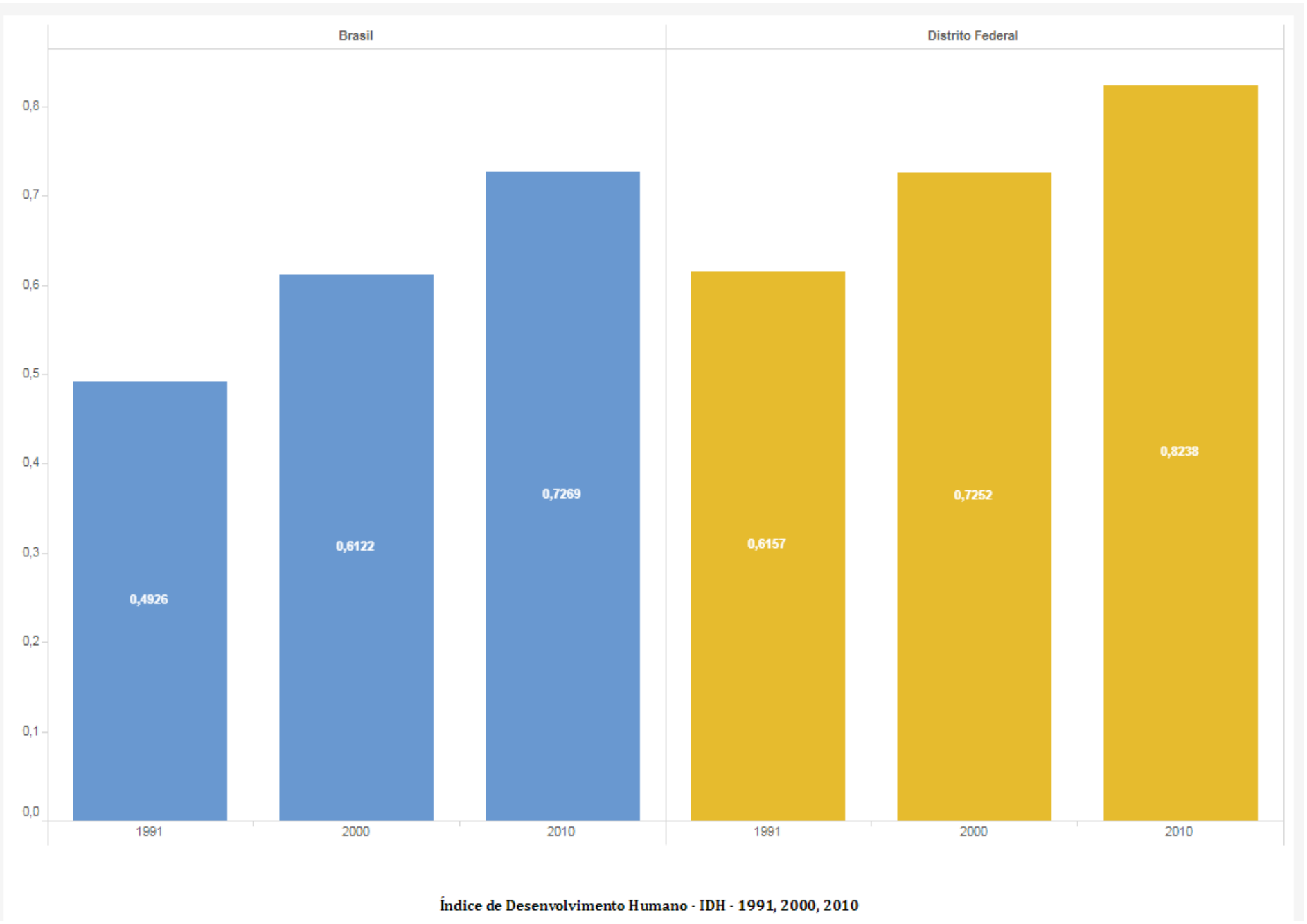

Fonte:Codeplan (2018) 
Figura 4 - Índice de Gini Brasil x DF

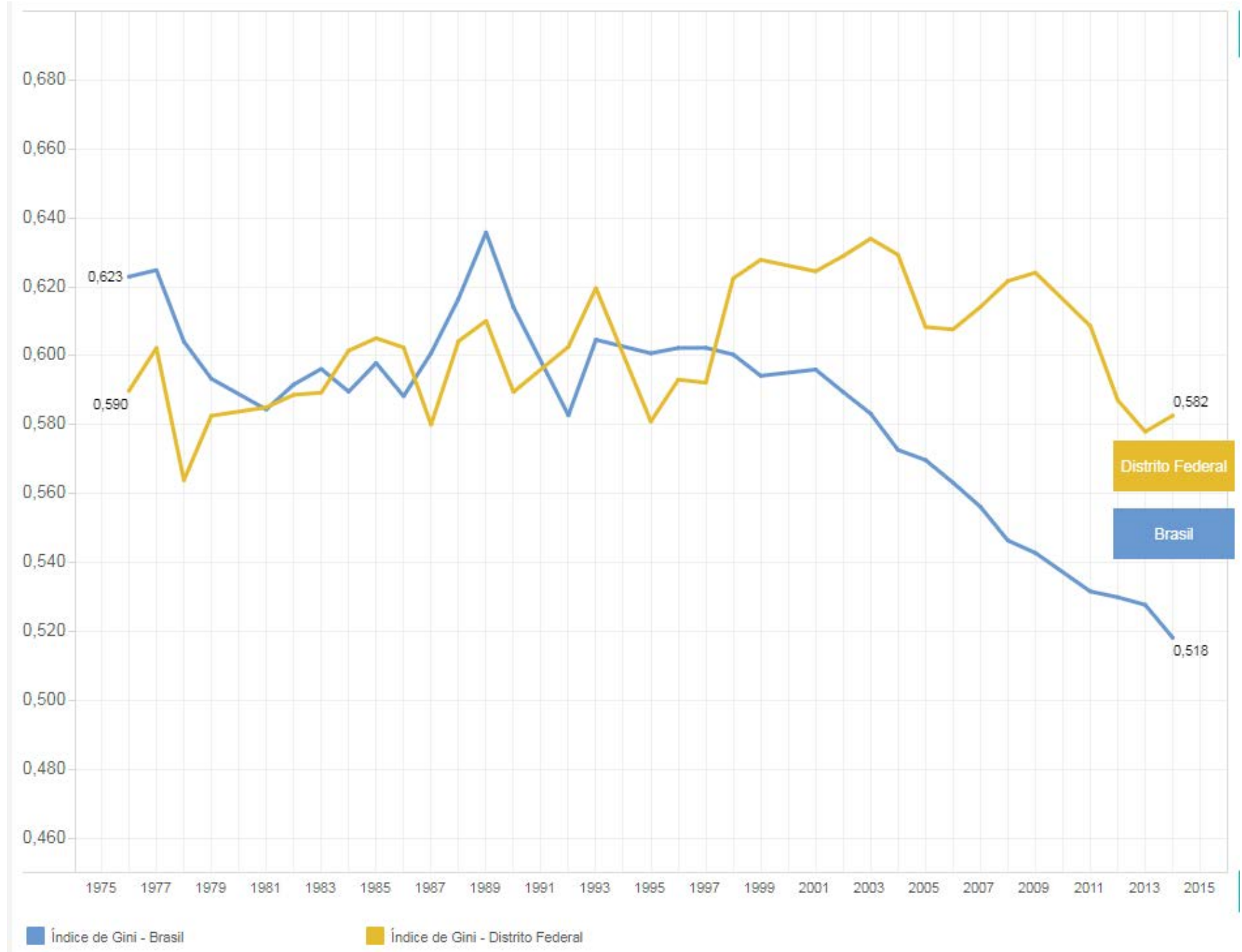

Fonte: PNAD (2018)

\subsection{População e amostragem}

Visando estabelecer uma contextualização social e demográfica da amostragem prioritária de pesquisa, foram utilizados dados da Pesquisa Distrital por Amostra de Domicílios - PDAD do ciclo 2015-2016, elaborado pela CODEPLAN, além de índices do IBGE e dados do próprio Governo do Distrito Federal. Que caracterizam e especificam o perfil da população analisada. 


\subsection{1 Águas Claras}

A implementação da RA de Águas Claras foi autorizada através da lei $n^{\circ}$ 3.153/2003, que desmembrou a RA de Taguatinga e tornou Águas Claras a XX RA do Distrito Federal. Com uma população estimada em 148.490 dividida em seus $31,5 \mathrm{~km}^{2}$ de extensão terroritorial.

Figura 5 - Mapa Águas Claras

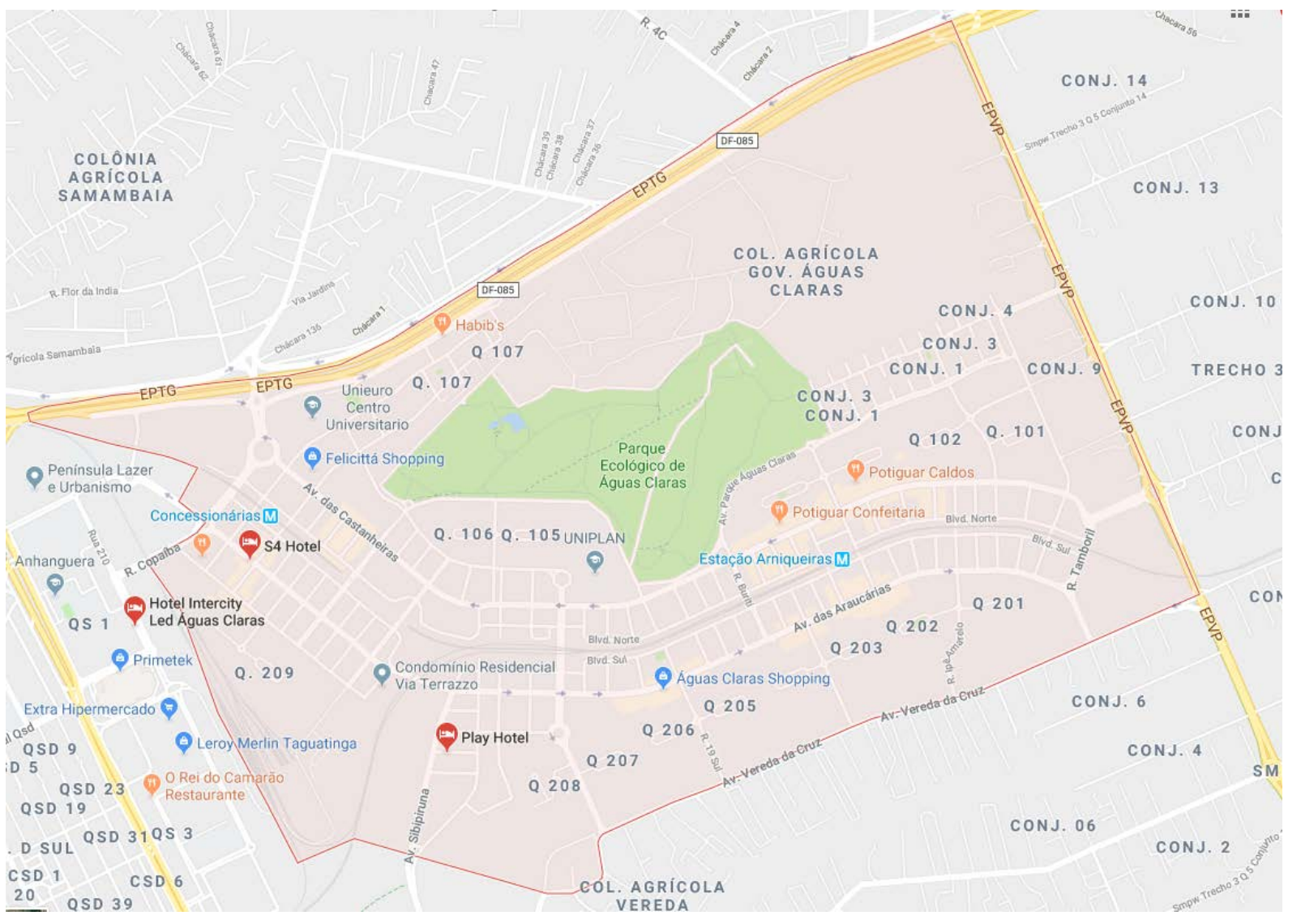

Fonte: Google Maps (2018)

De acordo com a Administração Regional de Águas Claras (2018) sua criação foi baseada na necessidade de expansão ordenada de Brasília, e principalmente na viabilização do metrô como ferramenta dessa ordenação, seguindo uma proposta racional de ocupação do solo.

Para consolidar essa proposta, Águas Claras é amplamente atendida pelo metrô, possuindo três estações: Arniqueiras, localizada na parte "baixa" da cidade, Águas Claras, que se encontra na parte central, e a Concessionárias, localizada na parte "alta". Segundo dados do PDAD (2016), a locomoção dos habitantes do bairro está dividida da seguinte forma: 
Tabela 8 - Locomoção Habitantes Águas Claras

\begin{tabular}{|c|c|c|c|c|c|c|c|c|}
\hline $\begin{array}{c}\text { Utilização } \\
\text { de } \\
\text { Transporte }\end{array}$ & \multicolumn{2}{|c|}{$\begin{array}{c}\text { Águas Claras } \\
\text { Total }\end{array}$} & \multicolumn{2}{c|}{$\begin{array}{c}\text { Águas Claras } \\
\text { Vertical }\end{array}$} & \multicolumn{2}{c|}{ Arniqueiras } & \multicolumn{2}{c|}{ Areal } \\
\cline { 2 - 9 } & $\mathbf{N}^{\circ}$ & $\%$ & $\mathbf{N}^{\circ}$ & $\%$ & $\mathbf{N}^{\circ}$ & $\%$ & $\mathbf{N}^{\circ}$ & $\%$ \\
\hline Ônibus & 9.142 & 12,42 & 2.329 & 4,72 & 3.211 & 24,25 & 3.603 & 32,47 \\
\hline Automóvel & 46.824 & 63,59 & 34.986 & 70,97 & 7.882 & 59,54 & 3.956 & 35,66 \\
\hline Utilitário & 70 & 0,09 & 0,00 & 0,00 & 36 & 0,27 & 34 & 0,30 \\
\hline Metrô & 9.221 & 12,52 & 8.860 & 17,97 & 108 & 0,82 & 253 & 2,28 \\
\hline Motocicleta & 956 & 1,30 & 341 & 0,69 & 397 & 3,00 & 219 & 1,97 \\
\hline Bicicleta & 402 & 0,55 & 57 & 0,12 & 126 & 0,95 & 219 & 1,97 \\
\hline A pé & 4.963 & 6,74 & 1.761 & 3,57 & 1.064 & 8,04 & 2.138 & 19,27 \\
\hline Outros & 2.054 & 2,79 & 966 & 1,96 & 415 & 3,13 & 673 & 6,07 \\
\hline Total & $\mathbf{7 3 . 6 3 2}$ & $\mathbf{1 0 0 , 0 0}$ & $\mathbf{4 9 . 2 9 8}$ & $\mathbf{1 0 0 , 0 0}$ & $\mathbf{1 3 . 2 4 0}$ & $\mathbf{1 0 0 , 0 0}$ & $\mathbf{1 1 . 0 9 4}$ & $\mathbf{1 0 0 , 0 0}$ \\
\hline
\end{tabular}

Fonte: Pesquisas Distritais por Amostra de Domicílio - PDAD (2016)

Dentro dessa realidade, onde os modais automotores, incluindo os estudados no presente trabalho concentram quase que $90 \%$ de todo o meio de transporte utilizado pelos residentes de Águas Claras, é importante caracterizar também a distribuição rodoviária da cidade, que conta com duas principais avenidas, nomeadas de Araucárias e Castanheiras, onde se encontram lojas comerciais, supermercados, academias e shoppings à sua margem, além de diversos edifícios residenciais, que estão expostos à poluição sonora dos veículos diariamente.

Em alguns pontos a distância das varandas dos apartamentos para a Avenida é inferior a 10 metros, tendo somente uma calçada os separando. Isso torna o ruído algo quase familiar às pessoas que trabalham ou moram nessas localidades que são particularmente próximas à fonte do barulho. Esse cenário ainda é mais agravante, quando percebemos os exemplos de ruídos que alguns ambientes produzem, como abaixo: 
Tabela 9 - Exemplos de Ruídos

\begin{tabular}{|c|c|}
\hline $35 \mathrm{~dB}(\mathrm{~A})$ & Biblioteca \\
\hline $65 \mathrm{~dB}(\mathrm{~A})$ & Escritórios com conversação normal \\
\hline $75 \mathrm{~dB}(\mathrm{~A})$ & Rua com intenso tráfego urbano \\
\hline $85 \mathrm{~dB}(\mathrm{~A})$ & Rua com tráfego de veículos pesados \\
\hline $130 \mathrm{~dB}(\mathrm{~A})$ & Decolagem de avião militar (30m) \\
\hline
\end{tabular}

Fonte: Zannin (2004) - Adaptado

Conhecida como o maior canteiro de obras da América Latina, Águas Claras tem uma previsão de em 2020 ter quase que sua totalidade construída, e uma população de 170.000 habitantes, o que reforçará ainda mais a necessidade de planejamento de ocupação e de transporte, principalmente o metrô.

A construção de ciclovias nas avenidas, e iniciativas governamentais visando à integração no transporte público visa diminuir a problemática do trânsito, que além da poluição sonora, também intensifica outros problemas de saúde pública, como stress, e poluição do ar.

Rogazzo (2013) exemplifica o aumento do tráfego urbano, ou seja, do trânsito seguindo a lógica de que a dependência automobilística no Brasil é uma consequência negativa causada pelo trânsito tratando-se de um círculo vicioso. Quanto mais pessoas migram para o transporte individual, mais carros há na rua, aumentando a intensidade do trânsito.

Esse padrão de comportamento faz com que diversas pessoas comecem a optar por mover-se de carro, já que além de ser mais rápido que o transporte público, é mais seguro e confortável.

\subsection{Instrumento(s) de pesquisa}

Por se tratar de um problema comumente identificado nas grandes cidades que possuem grandes regiões comerciais, locais de grande concentração de pessoas, e tráfego urbano, a medição da pressão sonora hoje é possível até mesmo por aplicativos de smartphones, sendo o mais famoso e disseminado deles, o sound meter. 
No presente estudo, foi utilizado um Termo-higro-decibelímetro-luxímetro mod. THDL-400 temperatura de -20 a $750^{\circ} \mathrm{C}$, Umidade de 25 a 95\%U.R. Decibelímetro de 35a 130 dB, Luxímetro de 0,01 a 200000 Lux, com função Max. Hold.

Figura 6 - Decibelímetro

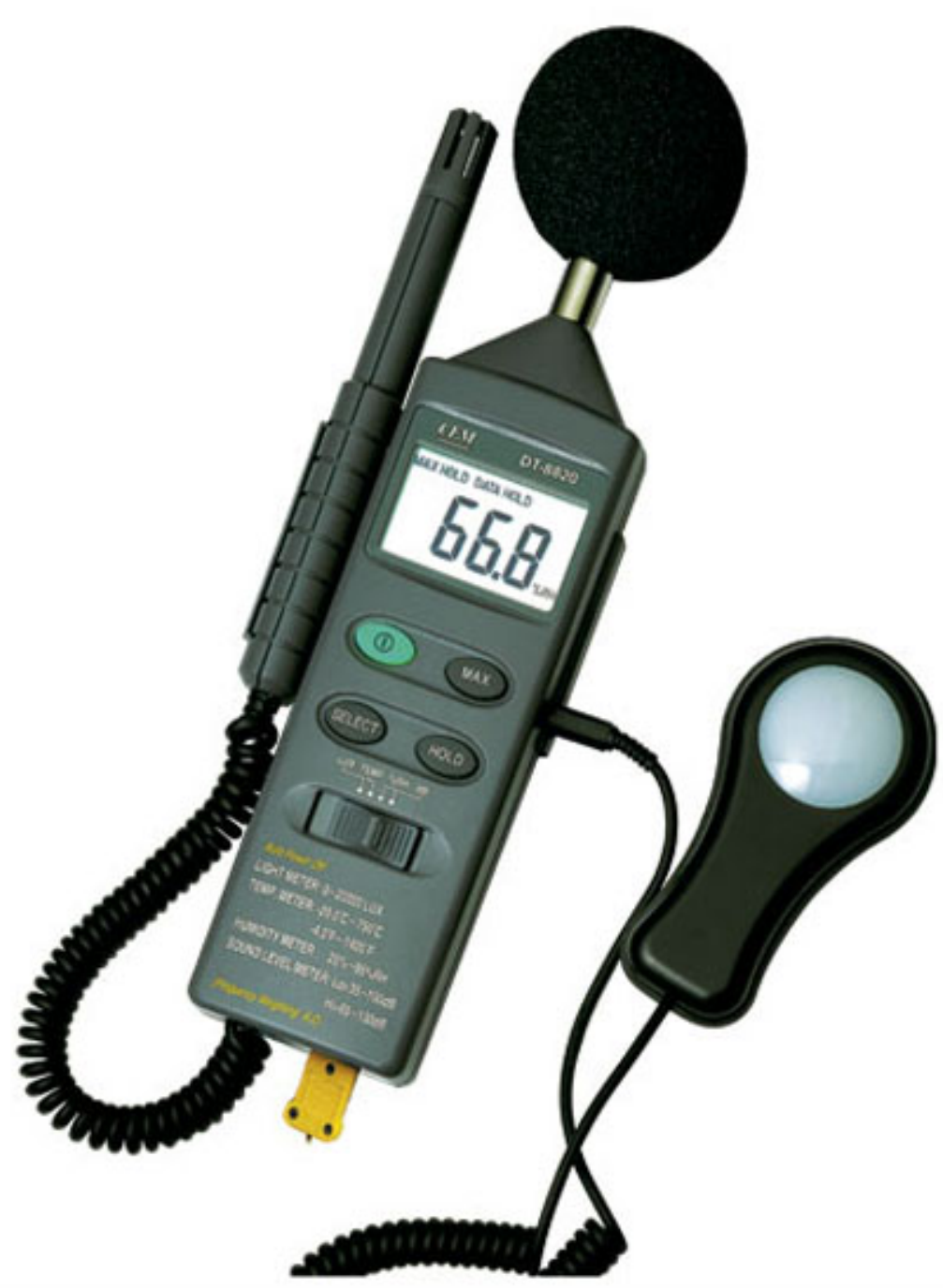

Fonte: Google (2018) 
Figura 7 - Decibelímetro

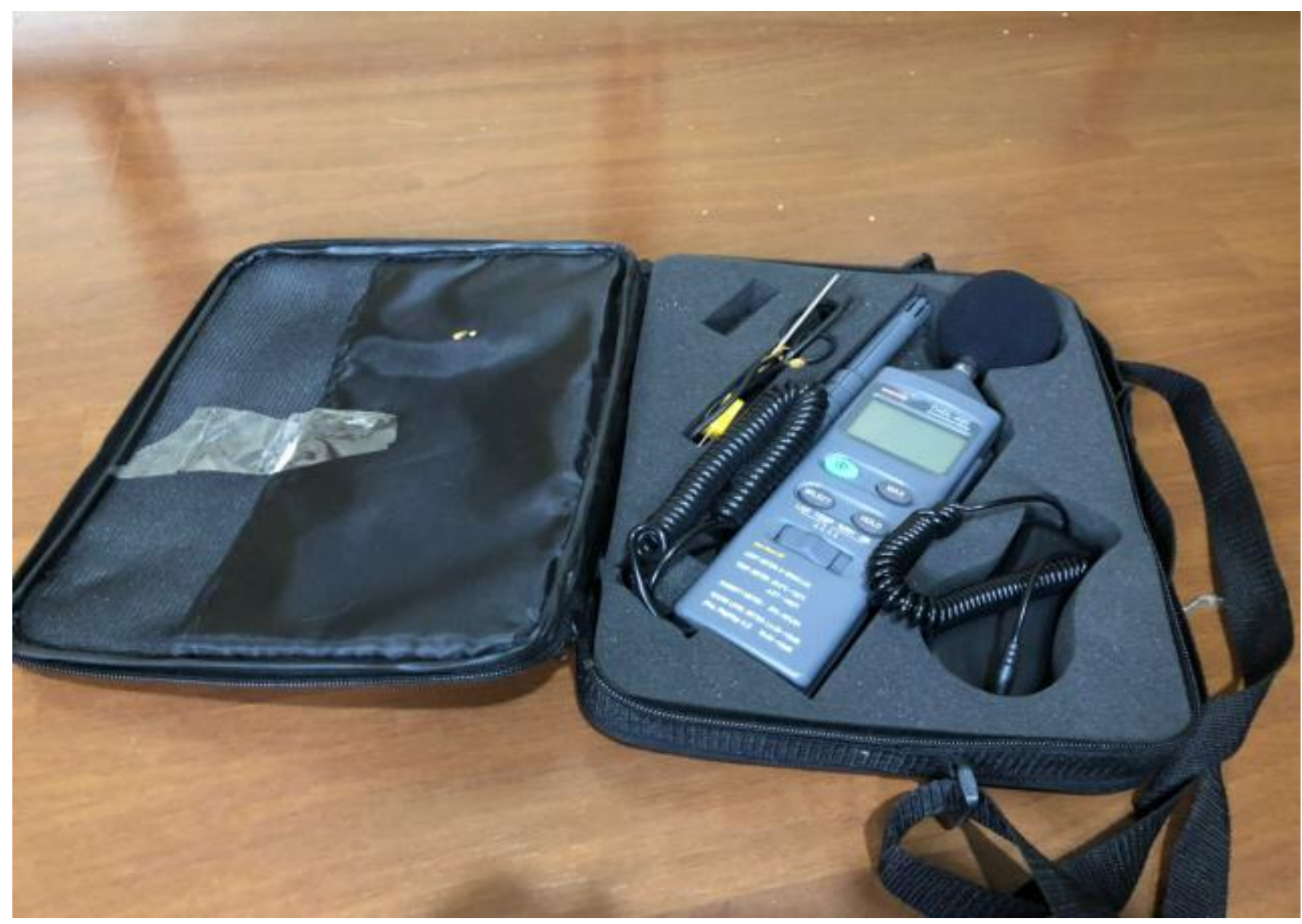

Fonte: Elaboração Própria (2018)

\subsection{Procedimentos de coleta e de análise de dados}

Após examinar minuciosamente a distribuição rodoviária e metroviária da RA de Águas Claras, foram definidos prioritariamente dois pontos de coleta. Um localizado em um ponto de ônibus situado entre as Ruas 30 e 31 Sul da Avenida das Araucárias. E o segundo localizado entre as Ruas 19 e 20 Sul, na via coletora nomeada como Boulevard Sul. 
Figura 8 - Ponto de Coleta Metroviário

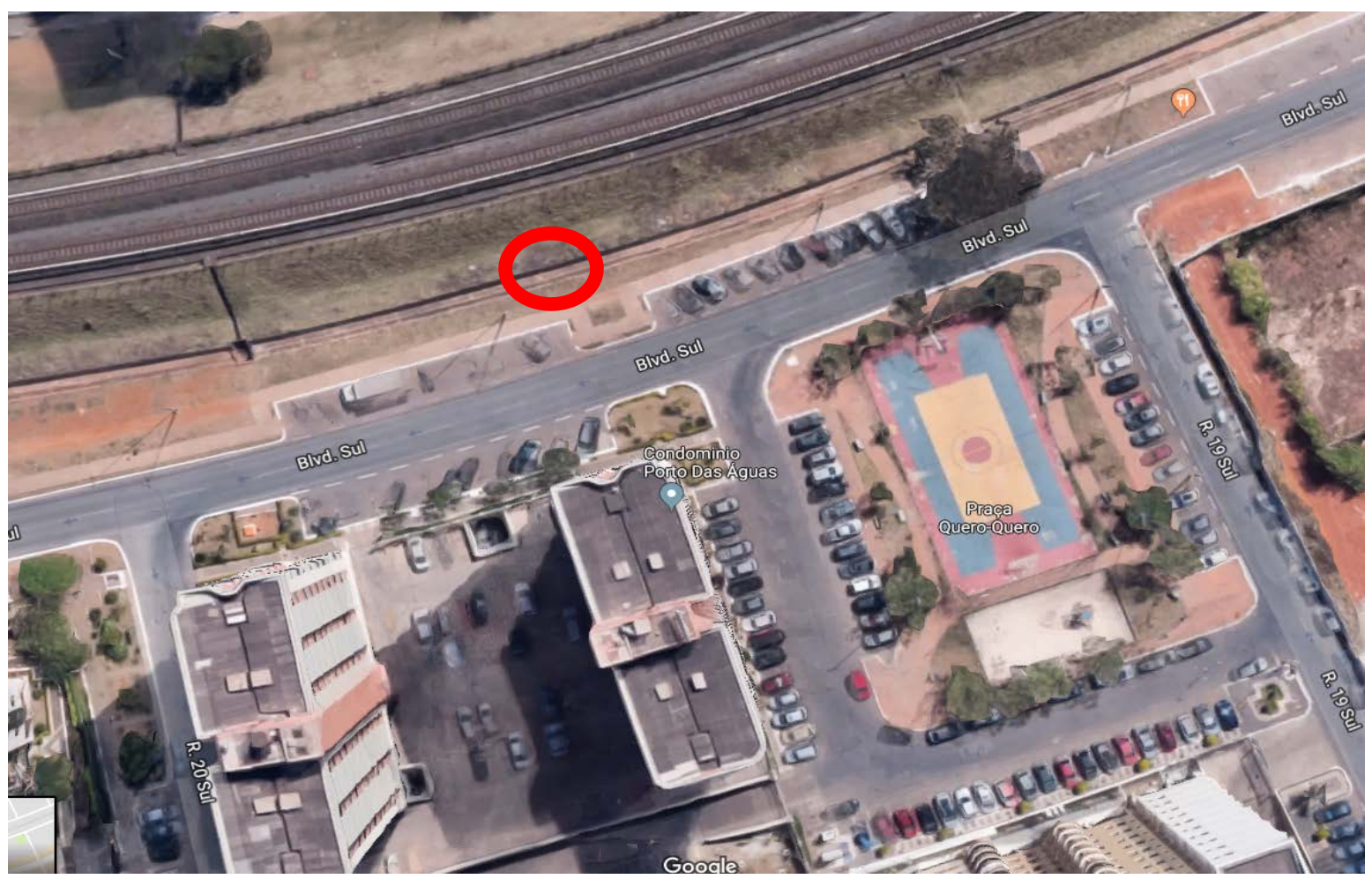

Fonte: Google Maps (2018)

Figura 9 - Ponto de Coleta Rodoviário

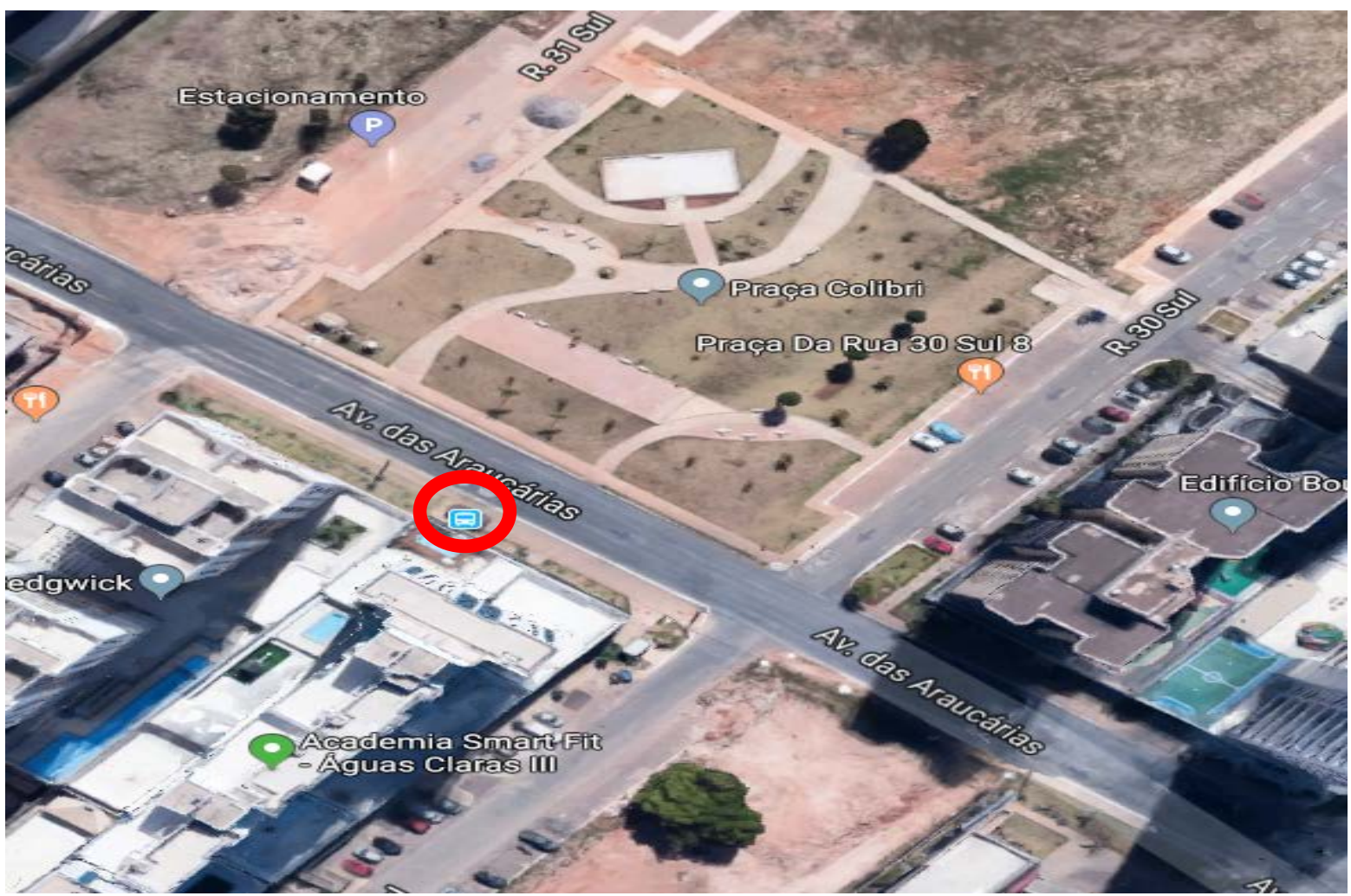

Fonte: Google Maps (2018) 
Tais pontos foram escolhidos, pois possuem quase a mesma distância das fontes sonoras, não tendo, portanto, discrepância de medições em favor de um ou outro modal de transporte. O ponto de ônibus está distante 2 metros da Avenida, enquanto o ponto de medição na Avenida Boulevard Sul está localizado a aproximadamente 5 metros do trilho do metrô.

Além disso, seguindo o objetivo estabelecido no início do presente trabalho, os pontos estão próximos de edifícios residenciais, onde é possível estabelecer uma análise da real inferência da poluição sonora dos modais estudados na residência dos moradores próximos aos pontos de coleta de dados, confrontando os resultados com a Legislação vigente.

Outro fator levado em consideração no momento da escolha dos locais de coleta foi a possível interferência do barulho de um dos modais na medição do outro. Para que isso não ocorresse, ambos os pontos de coleta estão isentos de interferência sonora um do outro, portanto não é perceptível nenhum barulho oriundo do metrô na parada de ônibus escolhida, e paralelamente a isso, não é permitida a circulação de ônibus nas vias coletoras denominadas Boulevard, tanto na Sul, quanto na Norte.

A coleta e análise dos dados em si, foi baseada na NBR 10151 da ABNT, que norteia e delimita os métodos de coleta, e os posteriores limites enquadrados na legislação brasileira. Sendo levados em consideração inclusive o período da medição, diurno ou noturno, e seus respectivos limites máximos permitidos por lei.

Embasado por tal norma, foram feitas coletas de dados em dias alternados da semana, como dias úteis e finais de semana, além de horários de maior e menor concentração de veículos nas vias, e de maior espaçamento entre um trem do metrô e outro. Totalizando por volta de 40h de medições em 2 pontos principais de coleta. 


\section{ANÁLISE DOS RESULTADOS}

Após realizadas as coletas nos moldes especificados do capítulo anterior, foram feitos cruzamentos de informações buscando confirmações de resultados já esperados, além da inferência de novas percepções, que somente a análise dos valores obtidos nas medições poderiam revelar.

Com esses dados em mãos e suas respectivas análises é possível diagnosticar com mais clareza, prognósticos para a racionalização do transporte público no que tange a poluição sonora e seus reflexos na população que com ela sofre. Isso significa que políticas e tendências podem ser melhor avaliadas e planejadas resultando em um melhoramento do transporte público coletivo do Distrito Federal e principalmente de Águas Claras.

\subsection{Modal Rodoviário}

Começando pelo modal rodoviário, realizando aproximadamente $20 \mathrm{~h}$ de medição no principal corredor rodoviário de Águas Claras, é possível observar o grande excesso de $\mathrm{dB}$ percebidos, comparados com a legislação vigentes e as recomendações dos Órgão de Saúde mundial. Enquanto a WHO alerta que limites acima de 65 dB são nocivos para a qualidade de vida humana e a NBR 1051 da ABNT limita também em $65 \mathrm{~dB}$ a poluição sonora em locais caracterizados como a Avenida usada como base de medição, os valores máximos medidos ultrapassaram em até $40 \%$ essas recomendações, conforme dados tabulados a seguir:

Tabela 10 - Dados ônibus

\begin{tabular}{|c|c|c|c|c|c|}
\cline { 2 - 6 } \multicolumn{1}{c|}{} & $\mathbf{2 5 / 0 4}$ & $\mathbf{2 6 / 0 4}$ & $\mathbf{2 7 / 0 4}$ & $\mathbf{0 5 / 0 5}$ & $\mathbf{0 6 / 0 5}$ \\
\hline Valor Máximo & $98,7 \mathrm{~dB}$ & $98,1 \mathrm{~dB}$ & $99,1 \mathrm{~dB}$ & $96,9 \mathrm{~dB}$ & $92,6 \mathrm{~dB}$ \\
\hline Valor Mínimo & $86,3 \mathrm{~dB}$ & $79,2 \mathrm{~dB}$ & $90,4 \mathrm{~dB}$ & $76,9 \mathrm{~dB}$ & $74,9 \mathrm{~dB}$ \\
\hline Média & $92,7 \mathrm{~dB}$ & $92,4 \mathrm{~dB}$ & $93,5 \mathrm{~dB}$ & $86,6 \mathrm{~dB}$ & $81 \mathrm{~dB}$ \\
\hline Desvio Padrão & $3,3 \mathrm{~dB}$ & $3,8 \mathrm{~dB}$ & $2,52 \mathrm{~dB}$ & $5,9 \mathrm{~dB}$ & $4,8 \mathrm{~dB}$ \\
\hline
\end{tabular}

Fonte: Elaboração Própria (2018) 
É perceptível portanto, a partir dos dados coletados o grande valor alcançando pelo modal rodoviário nos pontos máximos, chegando a quase $100 \mathrm{~dB}$, ou seja, $30 \mathrm{~dB}$ acima do recomendado. Mesmo nos finais de semana os índices apresentados apesar de representarem médias abaixo dos dias de semana, possuem pontos máximos bem acima do permitido por lei.

Grande parte desses valores pode ser atribuído à veículos com manutenção defasada, buzinas, alterações estruturais, além de estarem circulando acima da velocidade da via, estabelecida em $50 \mathrm{~km} / \mathrm{h}$.

\subsection{Modal Metroviário}

Levando em consideração os dados obtidos no modal metroviário é perceptível uma variação mínima das médias, mesmo nos finais de semana. Isso se deve à natureza sonora dos trens que não possuem muita variação independente do horário, e pela velocidade de segurança no qual o trem se desloca sobre o trilho, gerando valores muito próximos em cada passagem dos trens.

Tabela 11 - Dados Metrô

\begin{tabular}{|c|c|c|c|c|c|}
\cline { 2 - 6 } \multicolumn{1}{c|}{} & $\mathbf{1 8 / 0 4}$ & $\mathbf{1 9 / 0 4}$ & $\mathbf{0 2 / 0 5}$ & $\mathbf{1 0 / 0 5}$ & $\mathbf{1 2 / 0 5}$ \\
\hline Valor Máximo & $92,3 \mathrm{~dB}$ & $99,1 \mathrm{~dB}$ & $91,3 \mathrm{~dB}$ & $95,8 \mathrm{~dB}$ & $93,2 \mathrm{~dB}$ \\
\hline Valor Mínimo & $83,4 \mathrm{~dB}$ & $71,6 \mathrm{~dB}$ & $82,8 \mathrm{~dB}$ & $78,2 \mathrm{~dB}$ & $69,7 \mathrm{~dB}$ \\
\hline Média & $87,8 \mathrm{~dB}$ & $87,2 \mathrm{~dB}$ & $87,9 \mathrm{~dB}$ & $87,7 \mathrm{~dB}$ & $87,6 \mathrm{~dB}$ \\
\hline Desvio Padrão & $2,2 \mathrm{~dB}$ & $3,5 \mathrm{~dB}$ & $2,1 \mathrm{~dB}$ & $3,2 \mathrm{~dB}$ & $4,8 \mathrm{~dB}$ \\
\hline
\end{tabular}

Fonte: Elaboração própria (2018)

Apesar disso, os valores máximos também extrapolaram os recomendados por órgãos de saúde, principalmente em momentos onde o ruído do metrô somavase com o oriundo das ruas de acesso aos edifícios em momentos de grande circulação de veículos, como nas primeiras horas da noite. 
Outro fator que deve ser levado em consideração na análise desses dados é a velocidade de circulação dos trens do metrô. Foi perceptível a relação de quanto maior a velocidade, maiores os indicadores sonoros.

\subsection{Comparativo de Modais}

Trazendo os dados para uma comparação entre os dois modais, ônibus, e metrô de superfície, é possível perceber o mesmo valor máximo alcançado. De maneira geral a média do valor mínimo metroviário é menor do que a aferida pelos ônibus, e o desvio padrão metroviário também é ligeiramente menor, principalmente pela característica já exposta de que o trânsito tem natureza pulsante, que acaba gerando valores mais espaçados dentro da distribuição normal.

Tabela 12- Dados Comparados

\begin{tabular}{|c|c|c|}
\cline { 2 - 3 } \multicolumn{1}{c|}{} & Modal Rodoviário & Modal Metroviário \\
\hline Valor Máximo & $99,1 \mathrm{~dB}$ & $99,1 \mathrm{~dB}$ \\
\hline Valor Mínimo & $74,9 \mathrm{~dB}$ & $69,7 \mathrm{~dB}$ \\
\hline Média Max & $92,6 \mathrm{~dB}$ & $87,7 \mathrm{~dB}$ \\
\hline Média Normal & $77 \mathrm{~dB}$ & $70,2 \mathrm{~dB}$ \\
\hline Desvio Padrão & $4 \mathrm{~dB}$ & $3,1 \mathrm{~dB}$ \\
\hline
\end{tabular}

Fonte: Elaboração própria (2018)

\subsection{Relação com limites regulamentados}

De maneira alarmante, ao compararmos os decibéis aferidos com as recomendações da OMS, com as diretrizes da NBR 1051 e em particular com a Lei do Silêncio aqui no DF, as médias de ambos os modais ultrapassam muito os limites regulamentados. 
Tabela 13 - Comparativo Legislação

\begin{tabular}{|l|c|c|c|c|c|}
\cline { 2 - 6 } \multicolumn{1}{c|}{} & $\begin{array}{c}\text { MAX } \\
\text { HOLD }\end{array}$ & NORMAL & OMS & NBR 1051 & $\begin{array}{c}\text { Lei do } \\
\text { Silêncio }\end{array}$ \\
\hline Modal Rodoviário & $92,64 \mathrm{~dB}$ & $77,07 \mathrm{~dB}$ & $75 \mathrm{~dB}$ & $65 \mathrm{~dB}$ & $65 \mathrm{~dB}$ \\
\hline Modal Metroviário & $87,72 \mathrm{~dB}$ & $70,23 \mathrm{~dB}$ & $75 \mathrm{~dB}$ & $55 \mathrm{~dB}$ & $55 \mathrm{~dB}$ \\
\hline
\end{tabular}

Fonte: Elaboração própria (2018)

Essa análise dos resultados ganha contornos ainda mais graves quando os mesmos corroboram os dados da OMS, de que exposições acima de 75 decibéis por 8 horas diárias comprometem o perfeito funcionamento do organismo humano. Portanto, ao se estabelecer as médias encontradas, os trabalhadores do transporte público no DF estão sujeitos aos riscos dessa excessiva exposição. Justificando assim a classificação da OMS à poluição sonora como um problema de saúde pública mundial.

\section{CONSIDERAÇÕES FINAIS}

A elaboração do presente trabalho buscou encontrar respostas à importantes questões referentes à poluição sonora oriunda dos modais de transporte coletivo em uma das mais densas e movimentadas Regiões Administrativas do Distrito Federal, que possui características únicas nos quesitos, população, tráfego urbano, construção civil e comércio.

Para tanto, os objetivos específicos foram de vital importância no decorrer do trabalho, orientando e focando a elaboração do presente estudo, uma vez que por se tratar de um tema com ampla abordagem, e com extenso conteúdo, ter itens norteadores se mostrou uma grande estratégia para a conclusão da monografia. 


\begin{tabular}{|c|c|}
\hline Objetivos & Resultados \\
\hline $\begin{array}{l}\text { Identificar os impactos } \\
\text { gerados pela poluição } \\
\text { sonora dos modais } \\
\text { rodoviário e ferroviário; }\end{array}$ & $\begin{array}{l}\text { Através da Revisão Bibliográfica, foram levados } \\
\text { em conta dados de órgãos de saúde, além de estudos } \\
\text { relacionando os malefícios da poluição sonora com os } \\
\text { transportes citados. }\end{array}$ \\
\hline $\begin{array}{l}\text { - Coletar dados que } \\
\text { embasem o estudo; }\end{array}$ & $\begin{array}{c}\text { Foram realizadas 40h de medições, em } \\
\text { diferentes horas do dia e em diferentes dias da semana } \\
\text { afim de embasar o real impacto da poluição sonora em } \\
\text { águas claras }\end{array}$ \\
\hline $\begin{array}{l}\text { Comparar os resultados } \\
\text { de poluição sonora dos } \\
\text { modais de transporte } \\
\text { analisados; e }\end{array}$ & $\begin{array}{l}\text { Foram comparadas as médias, incluindo os } \\
\text { valores máximos atingidos entre os dois modais, além de } \\
\text { um comparativo com a legislação vigente. }\end{array}$ \\
\hline $\begin{array}{l}\text { - Interpretar os dados } \\
\text { colhidos, descrevendo os } \\
\text { impactos gerados pela } \\
\text { poluição sonora. }\end{array}$ & $\begin{array}{l}\text { Em conjunto com as medições realizadas e os } \\
\text { dados da área de saúde já citados, foram identificados } \\
\text { padrões de funcionamento dos modais, além de uma } \\
\text { conclusão a respeito do real impacto da poluição sonora } \\
\text { e uma análise com relação à legislação. }\end{array}$ \\
\hline
\end{tabular}

\subsection{Percepções do Autor}

Comparar os reais níveis sonoros causados pelos dois modais de transporte públicos mais utilizados na cidade revelou-se uma missão de extrema preponderância em muitos aspectos, que originalmente, passariam despercebidos aos olhos deste autor.

Portanto, seguem algumas conclusões que puderam ser interpretadas após feitas todas as etapas de elaboração da dissertação, sendo a principal delas o fato 
de que de maneira geral, levando-se em consideração as médias aferidas, o meio rodoviário emite sons de maior nível e intensidade do que o meio metroviário, corroborando o que Nunes (1999) já alertava de que o tráfego veicular, por ter característica pulsante, onde os veículos movem-se com sequências de acelerações e desacelerações é o maior contribuinte para o ruído ambiental. Além disso:

Os maiores índices de valores medidos foram oriundos de veículos já desgastados ou adulterados, como freios de ônibus com pastilhas gastas, motores com barulho excessivo durante o funcionamento e escapamentos de motos fora dos padrões de fábrica.

> Alguns pontos de ônibus da Avenida Araucárias não possuem o recuo característico para que o ônibus diminua a velocidade, sendo o mesmo obrigado a parar em uma das faixas da Avenida. Isso gera transtornos sonoros altíssimos como buzinas, freadas bruscas e até mesmo gritos.

> Grande parte das passagens de pedestre estão em estado deteriorado e sem sinalização devida, fazendo com que, novamente, transtornos sonoros oriundos de buzinas e freadas sejam aferidos por moradores, pedestres e passageiros próximos às vias.

$>$ Por estarem extremamente próximas das fontes de ruído, as residências às margens da Avenida e do trilho do metrô extrapolam até $30 \mathrm{~dB}$ quando se é levado em conta o ápice sonoro mensurado.

$>$ Por se tratar de uma RA ainda em expansão no que tange a construção civil, a circulação de caminhões e veículos pesados é constante, deteriorando ainda mais o já frágil equilíbrio sonoro da região.

Apesar da legislação limitar a poluição sonora no período da noite em 5 dB comparado com o período diurno, as médias quase não variaram entre um turno e outro, sendo até mesmo mais incômodo estar próximo do metrô à noite do que pela manhã.

Outro fator percebido foi a grande movimentação noturna das áreas onde foram realizadas as medições. A avenida é movimentada até tarde da noite, pois às margens da mesma se encontram academias, bares, restaurantes. Já o metrô têm horário de funcionamento até as $23 \mathrm{~h} 30$, ou seja, essas áreas não deixam de emitir ruídos com o final do dia. 
Durante a realização do trabalho também foi percebida a falta de conhecimento que a população em geral têm acerca do tema, e até mesmo a falta de importância que os passageiros, moradores e trabalhadores dão para o problema da poluição sonora. Por muitas vezes, durante as medições, o argumento de que aos poucos "a gente se acostuma" foi ecoado pelos presentes durante as medições.

Os resultados alcançados por esse trabalho também evidenciam a necessidade de um movimento governamental no tocante ao oferecimento de um transporte público de qualidade também no que tange à poluição sonora, principalmente levando em consideração o aspecto sustentável que o transporte coletivo carrega nos dias atuais.

Com o agravante demográfico do Distrito Federal, que centraliza os postos de trabalho, na maioria das vezes longe das residências dos trabalhadores, os passageiros passam a despender muitas horas sob ruídos que a OMS já classifica como danosos aos funcionamento dos sistemas nervoso, auditivo e cognitivo.

\subsection{Tendências}

Conforme já exposto durante o trabalho, o Brasil, e por consequência o DF possuem extrema dificuldade no planejamento e na execução de obras de infraestrutura que demandem investimentos maciços do governo, e tempo relativamente alto de conclusão de obras.

Dentro dessa característica singular, as barreiras acústicas em rodovias surgem como alternativa viável, rápida e de custo baixo para os governos municipais, estaduais e até governamentais. Conforme a Acoustic Control:

\footnotetext{
A barreira acústica em rodovias é uma obstrução sólida construída. Elas não bloquem completamente todo o ruído, porém a redução chega a níveis globais de barulhos aceitos pelas mais conceituadas instituições de medição sonora. Essa barreira acústica em rodovias pode ser formada a partir de montes de placas ao longo das estradas. Essas paredes artificiais funcionam como uma ferramenta eficaz e rápida para atenuar o ruído diferentes tipos, como em rodovias, aeroportos e estações de metrô. São fabricadas com
} 
minerais importados de alta densidade, à base de EPDM, e Rocha Basáltica.

Por apresentarem resultados satisfatórios a curto prazo, já são utilizadas em rodovias por toda a Europa, China e América do Norte, além de mercados emergentes mais parecidos com o brasileiro, como sudeste asiático e Índia.

Figura 10 - Barreira Acústica

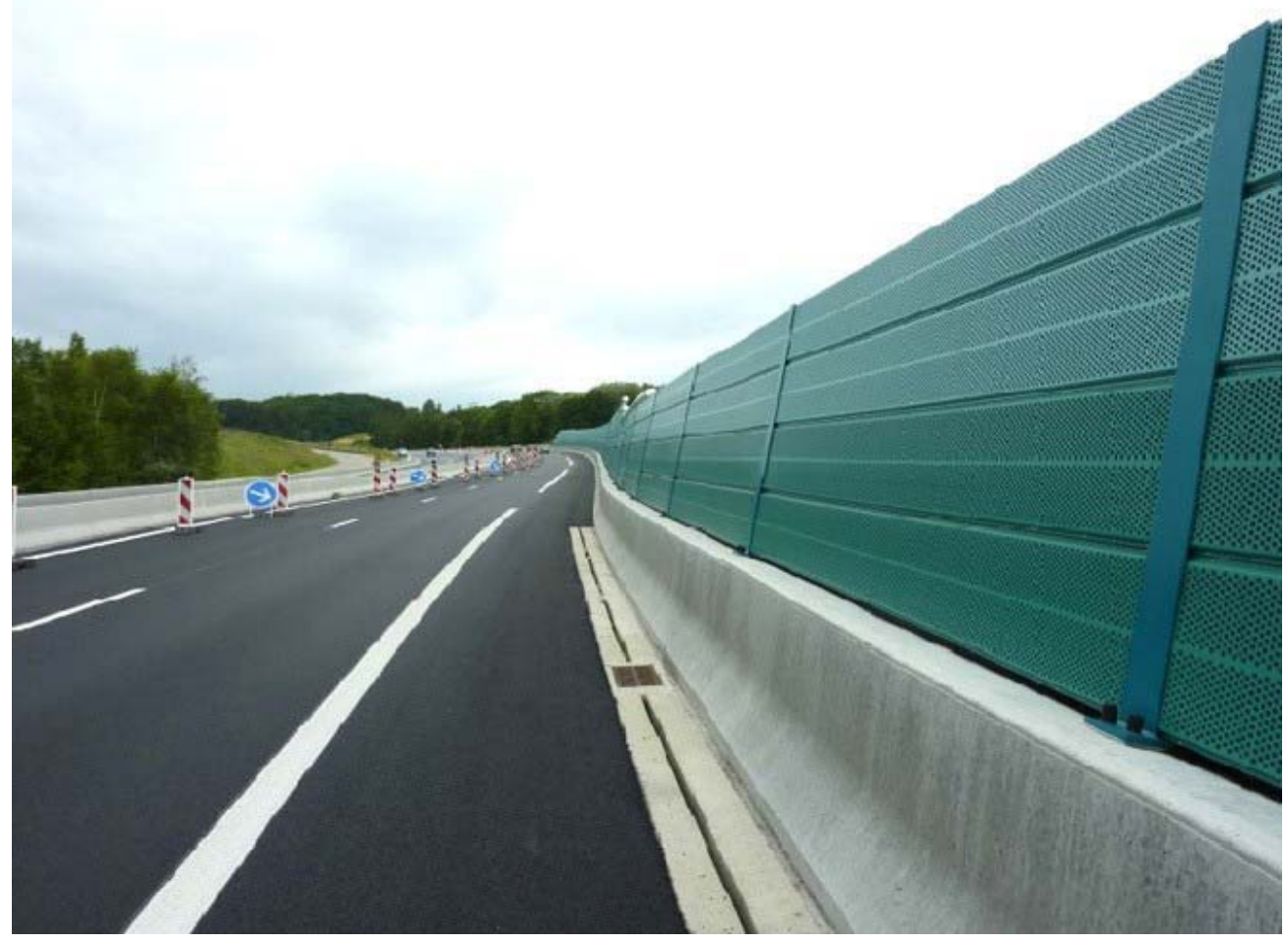

Fonte: Google (2018)

\subsection{Obstáculos}

É possível caracterizar também como um resultado da pesquisa, a constatação da ausência de normativos específicos que regulem o conforto sonoro dos passageiros e normatizem a utilização do transporte público no sentido de excesso de ruídos.

Além disso não há iniciativas no sentido de controlar os ruídos dos veículos, principalmente os automotores, o que torna o próprio calabouço institucional, 
um obstáculo a ser superado na tentativa de minimizar os efeitos da poluição sonora no transporte público coletivo e nas vias de rodagem.

Soma-se isso à ineficiência das medidas adotadas até o momento para diminuição dos ruídos nas rodovias e no transporte público, é necessário e urgente a adoção de medidas para o controle, monitoramento e posterior planejamento de políticas para a acústica nos modais de transporte público.

\subsection{Recomendações Futuras}

Corroborando as afirmações de Ribeiro (2009) a falta de manutenção das rodas, dos motores, dos carris, dos freios, dos mecanismos de criação de tração e de todos os outros mecanismos que fazem o comboio funcionar, pode provocar o aumento de ruído em significativos decibéis, que poderiam ser diminuídos, impactando positivamente na qualidade da viagem dos passageiros, e dos moradores ao redor das estações, vias e pontos de ônibus.

Portanto, um dos grandes aspectos vinculados à minimização dos impactos sonoros dentro do sistema de transporte coletivo encontrado na manutenção da frota rodoviária, e na malha de trilhos dos trens ferroviários, seria de extrema importância na mitigação da problemática estudada. 


\section{REFERÊNCIAS}

ABNT NBR 10.151. Acústica - Avaliação do ruído em áreas habitadas, visando o conforto da comunidade - Procedimento. Rio de Janeiro, 2000.

AMORIM, A. E. B. et al. Previsão do ruído ambiental urbano devido à implantação do Modal Veículo Leve sobre Trilhos (VLT) por meio de simulação computacional. INTERAÇÕES, Campo Grande, v. 18, n. 4, p. 81-97, out./dez. 2017.

ARAÚJO, M. R. M., OLIVEIRA, J. M., JESUS, M. S., SÁ, N. R., SANTOS, P. A. C., \& LIMA, T. C. (2011). Transporte público coletivo: discutindo acessibilidade, mobilidade e qualidade de vida. Psicologia \& Sociedade, 23(2), 574-582.

BARBIERI, J. C. et al. INOVAÇÃO E SUSTENTABILIDADE: NOVOS MODELOS E PROPOSIÇÕES. RAE - Revista de Administração de Empresas, São Paulo, v. 50 , n. 2, p. 146-154, abr./jun. 2010.

BARBIERI, JOSÉ CARLOS; SILVA, DIRCEU DA. Desenvolvimento Sustentável e Educação Ambiental: Uma trajetória comum com muitos desafios. RAM. Revista de Administração Mackenzie, São Paulo, v. 12, n. 3, p. 51-82, mai./jun. 2011.

BLOOM, B. S. et al. Taxonomy of educational objectives. New York: David Mckay, 1956. 262 p. (v. 1);

CAMPOS, Lucila Maria De Souza; MELO, Daiane Aparecida De. Indicadores de desempenho dos Sistemas de Gestão Ambiental (SGA): uma pesquisa teórica. Produção, Rio de Janeiro, v. 18, n. 3, p. 540-555, set./dez. 2008.

COSTA, Milene Coutinho Lourenço. IMPACTOS NO ENTORNO DE PÓLOS GERADORES DE TRÁFEGO. 2011. 143 f. Dissertação (Mestrado em Desenvolvimento e Meio Ambiente Urbano) - Universidade da Amazônia, Belém, 2011. 
CIRIBELLI, Marilda Corrêa. Como elaborar uma dissertação de Mestrado através da pesquisa científica. Marilda Ciribelli Corrêa, Rio de Janeiro: 7 Letras, 2003.

DA SILVA, Marcos Santos. O impacto da Poluição Sonora nos usuários do transporte coletivo da cidade de Goiânia. 2003. Dissertação (Programa de Pós Graduação) - Gestão Ambiental, Universidade Católica de Brasília, Brasília.

DAMBRÓS, Marianne Macedo Goulart; SENNA, Ana Júlia Teixeira; ALVES, Ricardo Ribeiro. Gestão ambiental no setor público: percepção dos servidores da prefeitura municipal de São Gabriel (RS). Revista do Centro do Ciências Naturais e Exatas UFSM, Santa Maria, v. 18, n. 2, p. 674-689, mai./ago. 2014.

DIRECTIVE 2002/49/EC OF THE EUROPEAN PARLIAMENT AND OF THE COUNCIL. Relating to the assessment and management of environmental noise. 2002.

GANIME, Almeida Da Silva. O RUÍDO COMO UM DOS RISCOS OCUPACIONAIS: UMA REVISÃO DE LITERATURA. Enfermaria Global, Murcia, n. 19, p. 1-15, jun. 2010.

GIL, A. C. Métodos e Técnicas de Pesquisa Social, 6 $^{\mathbf{a}}$ ed. São Paulo: Atlas, 2011.

GONÇALVES, P. H. et al. Análise do ruído de casas noturnas e bares em áreas residenciais de anápolis-go e o impacto na vizinhança. REVISTA MIRANTE, Anápolis, v. 9, n. 2, p. 268-282, dez. 2016.

GOROMOSOV, M. S. The physiological basis of health stadndars for dwellings. Gengra, Weold Healtu Organization. Public Health Papers, n.33, 1968.

JABBOUR, Charbel José Chiappetta; SANTOS, Fernando César Almada; BARBIERI, José Carlos. RAC - Revista de Administração Contemporânea, Rio de Janeiro, v. 12, n. 3, p. 689-715, jul./set. 2008. 
SUPERIOR TRIBUNAL DE JUSTIÇA. Poluição sonora: o barulho que incomoda até a Justiça. Disponível em <https://stj.jusbrasil.com.br/noticias/100385423/poluicao-sonora-o-barulho-queincomoda-ate-a-justica> Acesso em Mar 2018.

MARTINS, Maria Rosa Selvati; SILVA, José Geraldo Ferreira Da. O sistema de gestão ambiental baseado na ISO 14000: Importância do instrumento no caminho da sustentabilidade ambiental. Revista do Centro do Ciências Naturais e Exatas UFSM, Santa Maria, v. 18, n. 4, p. 1460-1466, dez. 2014.

MMA. Resolução Conama $n^{\circ}$ 2, de 8 de março de 1990. Disponível em http://www.mma.gov.br/port/conama/legiabre.cfm?codlegi=99. Acesso em Abr. 2018.

NEGRÃO, Alexandra Maria Góes. Urbanização e poluição sonora: estudo de caso sobre os efeitos extra-auditivos provocados pelo ruído noturno urbano. 2009. 77 f. Dissertação (Mestrado em Desenvolvimento e Meio Ambiente Urbano) Universidade da Amazônia, Belém, 2009.

PADOIN, Andréa Inês Vogt E Lizandra D.; JÚNIOR, José Luiz Goldschmidt; ROSA, Leoni P. Godoy E Leandro C.. Importância do sistema de gestão ambiental na empresa - estudo de caso.. [S.L.: s.n.], 1998.

PDAD - Pesquisa Distrital por Amostra de Domicílios - Águas Claras 2015/2016. SEPLAN/DF, 2016

QUIPUNGO, P. F. et al. PERCEPÇÃO DA QUALIDADE NO SERVIÇO DE TRANSPORTE PÚBLICO URBANO E DE SEUS IMPACTOS AMBIENTAIS NO DISTRITO FEDERAL - DF - BRASIL. Revista do CEPE, Santa Cruz do Sul, n. 44, p. 100-112, jul./dez. 2016.

RAGAZZO, Carlos Emmanuel Joppert; LIMA, João Marcelo Da Costa E Silva. Planejamento urbano e redução de trânsito: o caso da estação de metrô da Nossa Senhora da Paz, em Ipanema. Revista Brasileira de Gestão Urbana, Paraná, v. 5, n. 2, p. 97-113, jul./dez. 2013. 
RIBEIRO, Nuno Miguel Pereira. Barreiras Sonoras em Alta Velocidade Ferroviária. Dissertação - Mestrado em Engenharia Civil, Universidade do Porto, Portugal.

RIETVELD, Piet. Infrastructure and regional development: A survey of multiregional economic models. The annals of Regional Science. Amsterdam, The Netherlands, 1989.

RODRIGUES, E. C. POLÍTICA PÚBLICA DE TRANSPORTE METROVIÁRIO COMO FATOR DE IMPACTO NO MERCADO IMOBILIÁRIO E NA ARRECADAÇÃO DE IMPOSTOS. In: $17^{\circ}$ PANAM - Congresso Panamericano de Engenharia de Trânsito, Transporte e Logística, 2012, Santiago, Chile. PANAM 2012 - Santiago, Chile. Santiago, Chile: PANAM 2012 - Universidade dos Andes - Chile, 2012. v. 1. p. 114-126;

SEIFFERT, M. E. B. Gestão ambiental: instrumentos, esferas de ação e educação ambiental. São Paulo: Atlas, 2009. 310p.

TINOCO, João Eduardo Prudêncio; ROBLES, Léo Tadeu. A contabilidade da gestão ambiental e sua dimensão para a transparência empresarial: estudo de caso de quatro empresas brasileiras com atuação global. Revista de Administração Pública, Rio de Janeiro, v. 40, p. 1077-1096, nov./dez. 2006.

Transport Environment (2008). Disponível em < https://www.transportenvironment.org/> Acesso em Abr 2018.

VILLAVICENCIO, José Roberto Rodriguez; BODMER, Milena; MARTINS, Jorge. Os Clientes e os seus Critérios de Escolha dos Serviços de Transporte Público Urbano. XIII SIMPEP, Bauru, p. 1-12, nov. 2006.

WHO. WORLD HEALTH ORGANIZATION. Guidelines for community noise, 1999.

WHO. WORLD HEALTH ORGANIZATION. Burden of disease from environmental noise: Quantification of healthy life years lost in Europe, 2011. 


\section{APÊNDICES}

Apêndice A - Compilado de fotos das coletas de dados
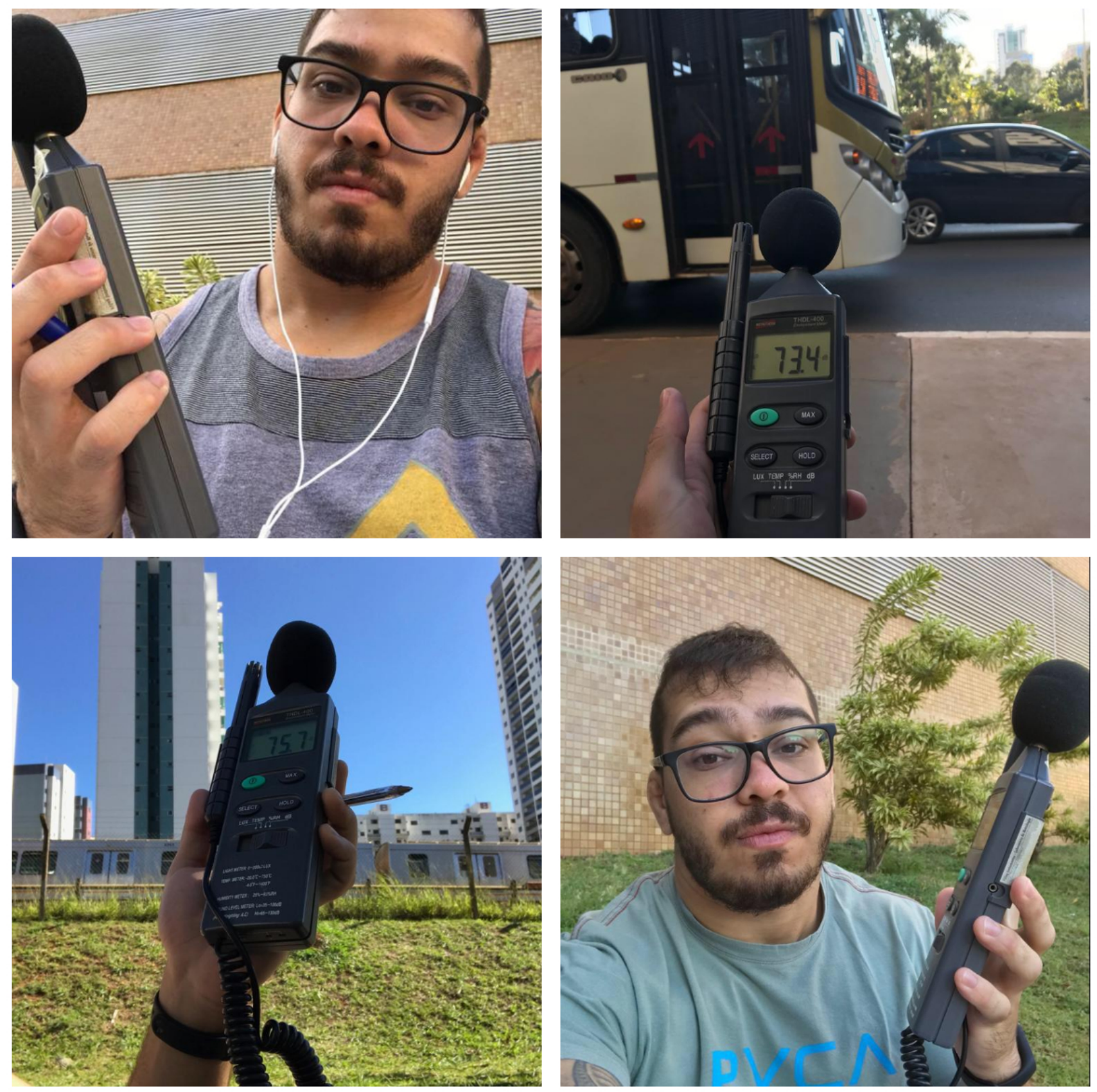
Apêndice B - Tabulações de Dados de Coletas Rodoviário

$25 / 04 / 2018$

\begin{tabular}{|c|c|c|c|c|}
\hline Média & Mediana & Máximo & Mínimo & Desvio Padrão \\
\hline $\mathbf{9 2 , 7 4 8 3 9}$ & 92,7 & 98,7 & 86,3 & 3,303116808 \\
\hline & & & & \\
\hline Média & Mediana & Máximo & Mínimo & Desvio Padrão \\
\hline 76,7 & 76,9 & 82,4 & 70,9 & 3,067028964 \\
\hline
\end{tabular}

$25 / 04 / 2018$

\begin{tabular}{|c|c|c|c|c|}
\hline Média & Mediana & Máximo & Mínimo & Desvio Padrão \\
\hline $\mathbf{9 2 , 3 7 1 0 5}$ & 92,35 & 98,7 & 87,6 & 2,387796439 \\
\hline
\end{tabular}

\begin{tabular}{|c|c|c|c|c|}
\hline Média & Mediana & Máximo & Mínimo & Desvio Padrão \\
\hline $\mathbf{7 8 , 4 3 1 5 8}$ & $\mathbf{7 7 , 9}$ & $\mathbf{8 3 , 4}$ & $\mathbf{7 2 , 2}$ & $\mathbf{3 , 1 6 0 6 6 2 3 7 2}$ \\
\hline
\end{tabular}

\begin{tabular}{c|c|c|c|c|}
\hline & \multicolumn{5}{|c}{$26 / 04 / 2018$} \\
Média & Mediana & Máximo & Mínimo & Desvio Padrão \\
\hline $\mathbf{9 2 , 4 3 2 4 3}$ & $\mathbf{9 2 , 8}$ & $\mathbf{9 8 , 1}$ & $\mathbf{7 9 , 2}$ & $\mathbf{3 , 8 3 8 1 8 5 2 2 8}$ \\
\hline
\end{tabular}

\begin{tabular}{|c|c|c|c|c|}
\hline Média & Mediana & Máximo & Mínimo & Desvio Padrão \\
\hline $\mathbf{7 5 , 5 5 5 8 6}$ & $\mathbf{7 6 , 8}$ & $\mathbf{8 3 , 2}$ & $\mathbf{6 1 , 2}$ & $\mathbf{4 , 2 9 3 5 1 9 1 0 5}$ \\
\hline
\end{tabular}

$27 / 04 / 2018$

\begin{tabular}{|c|c|c|c|c|}
\hline Média & Mediana & Máximo & Mínimo & Desvio Padrão \\
\hline 93,575 & 92,75 & 99,7 & 90,4 & 2,524637854 \\
\hline Média & Mediana & Máximo & Mínimo & Desvio Padrão \\
\hline 74,89286 & 74,15 & 82,8 & 70,8 & 3,112451525 \\
\hline
\end{tabular}


05/05/2018

\begin{tabular}{|c|c|c|c|c|}
\hline Média & Mediana & Máximo & Mínimo & Desvio Padrão \\
\hline $\mathbf{8 6 , 6 0 6 6 7}$ & $\mathbf{8 6 , 8 5}$ & 96,9 & 76,9 & 5,925743564 \\
\hline Média & Mediana & Máximo & Mínimo & Desvio Padrão \\
\hline 73,21333 & 72,7 & 79,6 & 67,3 & 3,422212768 \\
\hline
\end{tabular}

$06 / 05 / 2018$

\begin{tabular}{|c|c|c|c|c|}
\hline Média & Mediana & Máximo & Mínimo & Desvio Padrão \\
\hline $\mathbf{8 1 , 0 7 6 1 9}$ & $\mathbf{7 9 , 8}$ & $\mathbf{9 2 , 6}$ & $\mathbf{7 4 , 9}$ & $\mathbf{4 , 8 6 0 0 3 1 3 5 4}$ \\
\hline Média & Mediana & Máximo & Mínimo & Desvio Padrão \\
\hline 72,86667 & 71,6 & 81,9 & 65,4 & 5,111294683 \\
\hline
\end{tabular}

Apêndice C - Tabulações de Dados de Coletas Metroviário

\begin{tabular}{c|c|c|c|c|}
\hline & \multicolumn{3}{|c}{$18 / 04 / 2018$} \\
\hline Média & Mediana & Máximo & Mínimo & Desvio Padrão \\
\hline $\mathbf{8 7 , 8 6 1 9 0 4 7 6}$ & $\mathbf{8 8 , 1 5}$ & $\mathbf{9 2 , 3}$ & $\mathbf{8 3 , 4}$ & $\mathbf{2 , 2 9 7 8 2 0 0 0 4}$ \\
\hline Média & Mediana & Máximo & Mínimo & Desvio Padrão \\
\hline $\mathbf{6 9 , 6 4 7 6 1 9 0 5}$ & $\mathbf{6 9 , 2 5}$ & $\mathbf{7 5 , 6}$ & $\mathbf{6 2 , 3}$ & $\mathbf{2 , 8 1 0 1 0 7 0 2 8}$ \\
\hline
\end{tabular}

$19 / 04 / 2018$

\begin{tabular}{|c|c|c|c|c|}
\hline Média & Mediana & Máximo & Mínimo & Desvio Padrão \\
\hline $\mathbf{8 7 , 2 9 2 2 3}$ & $\mathbf{8 7 , 2}$ & 99,1 & 71,6 & $\mathbf{3 , 5 8 0 6 5 8 5 3 6}$ \\
\hline Média & Mediana & Máximo & Mínimo & Desvio Padrão \\
\hline 69,47767 & 69,8 & 77,8 & 53,2 & 4,38504437 \\
\hline
\end{tabular}




\begin{tabular}{|c|c|c|c|c|}
\hline & \multicolumn{3}{|c}{ 02/05/2018 } \\
\hline Média & Mediana & Máximo & Mínimo & Desvio Padrão \\
\hline $\mathbf{8 7 , 9 5 6}$ & $\mathbf{8 7 , 7}$ & $\mathbf{9 1 , 3}$ & $\mathbf{8 2 , 8}$ & $\mathbf{2 , 1 4 0 1 0 9 0 3 1}$ \\
\hline Média & Mediana & Máximo & Mínimo & Desvio Padrão \\
\hline 72,388 & 72,6 & 79,3 & 64,1 & 4,57778306 \\
\hline
\end{tabular}

$10 / 05 / 2018$

\begin{tabular}{|c|c|c|c|c|}
\hline Média & Mediana & Máximo & Mínimo & Desvio Padrão \\
\hline $\mathbf{8 7 , 7 3 6}$ & $\mathbf{8 7 , 7}$ & 95,8 & 78,2 & 3,230894234 \\
\hline & & & & \\
\hline Média & Mediana & Máximo & Mínimo & Desvio Padrão \\
\hline $\mathbf{7 1 , 2 1 2}$ & 71,9 & 79,7 & 63,1 & 4,110645215 \\
\hline
\end{tabular}

$12 / 05 / 2018$

\begin{tabular}{|c|c|c|c|c|}
\hline Média & Mediana & Máximo & Mínimo & Desvio Padrão \\
\hline $\mathbf{8 7 , 6}$ & $\mathbf{8 8 , 5}$ & $\mathbf{9 3 , 2}$ & $\mathbf{6 9}, \mathbf{7}$ & $\mathbf{4 , 8 1 6 3 7 8 3 0 7}$ \\
\hline
\end{tabular}

\begin{tabular}{|c|c|c|c|c|}
\hline Média & Mediana & Máximo & Mínimo & Desvio Padrão \\
\hline $\mathbf{6 8 , 2 6 8}$ & $\mathbf{6 8 , 4}$ & $\mathbf{7 7 , 5}$ & $\mathbf{5 8 , 7}$ & $\mathbf{5 , 1 8 3 3 6 4 4 1 6}$ \\
\hline
\end{tabular}

